\title{
The stem cell division theory of cancer
}

\author{
Miguel López-Lázaro
}

Department of Pharmacology, Faculty of Pharmacy, University of Seville, C/ Profesor Garcia Gonzalez 2, 41012 Sevilla, Spain; mlopezlazaro@us.es; Tel: +34-954-55-63-48. Fax: +34-954-23-37-65

\begin{abstract}
All cancer registries constantly show striking differences in cancer incidence by age and among tissues. For example, lung cancer is diagnosed hundreds of times more often at age 70 than at age 20, and this cancer in nonsmokers occurs thousands of times more frequently than heart cancer in smokers. An analysis of these differences using basic concepts in cell biology indicates that cancer is the end-result of the accumulation of cell divisions in stem cells. In other words, the main determinant of carcinogenesis is the number of cell divisions that the DNA of a stem cell has accumulated in any type of cell from the zygote. Cell division, process by which a cell copies and separates its cellular components to finally split into two cells, is necessary to produce the large number of cells required for living. However, cell division can lead to a variety of cancer-promoting errors, such as mutations occurring during DNA replication, chromosome aberrations arising during mitosis, errors in the distribution of cell-fate determinants between the daughter cells, and failures to restore physical interactions with other tissue components. Some of these errors are spontaneous, others are promoted by endogenous DNA damage occurring during quiescence, and others are influenced by pathological and environmental factors. The cell divisions required for carcinogenesis are primarily caused by multiple local and systemic physiological signals rather than by errors in the DNA of the cells. As carcinogenesis progresses, the accumulation of DNA errors promotes cell division and eventually triggers cell division under permissive extracellular environments. The accumulation of cell divisions in stem cells drives not only the accumulation of the DNA alterations required for carcinogenesis, but also the formation and growth of the abnormal cell populations that characterize the disease. This model of carcinogenesis provides a new framework for understanding the disease and has important implications for cancer prevention and therapy.
\end{abstract}

Keywords: cancer etiology; carcinogenesis; cancer prevention; stem cells; cancer stem cells; stem cell environment; cells of origin in cancer; somatic mutation theory of cancer

\section{Introduction}

Cancer is a disease characterized by the formation and growth of abnormal cell populations that threaten the life of an individual by interfering with vital body functions. Although cancer is known to be ultimately caused by an uncontrolled cell proliferation, the main biological cause of the disease remains poorly understood [1]. An important clue came from analyses of cancer statistics by age carried out in the 1950s. These studies showed that, within the age group 25-74 years, cancer mortality increased exponentially with age $[2,3]$. These early works revealed that cancer was the end-result of several successive cellular changes. If cancer were caused by only one cellular change, or by several changes occurring simultaneously, these changes could occur at any moment in life, and cancer mortality would be rather similar in different age groups after a latency period [3]. Because DNA is the only cellular component that can accumulate and transmit changes throughout life (from zygote to death), it soon became accepted that carcinogenesis required the multistep accumulation of DNA changes.

According to a prevailing model of carcinogenesis, generally referred to as the somatic mutation theory, these DNA changes are mutations in oncogenes and tumor-suppressor genes. Mutations in oncogenes would activate cell proliferation, whereas mutations in tumor-suppressor genes would inhibit cell death or cell-cycle arrest. The multistep accumulation of three mutations in these genes in a specific order would suffice for a cell to evolve into an advanced cancer [4,5]. Cancer would be the result of the gradual accumulation of driver gene mutations that successively increase cell proliferation [6-8].

Several lines of evidence, however, challenge this prevailing theory of cancer. First, the somatic mutation theory is largely supported by the idea that cancer incidence increases exponentially with age. Since 
our cells are known to accrue mutations throughout life $[9,10]$, the accumulation of driver gene mutations in our cells would perfectly explain why the risk of cancer increases until death. However, this idea is based on analyses of cancer statistics by age carried out in the 1950s, in which data for the age groups above 75 years were considered unreliable and were excluded [3]. It is now well established that cancer incidence does not increase exponentially with age until death; it decelerates or decreases late in life for most cancers (Figure 1). For example, according to SEER cancer statistics review, 1975-2014, men in their 80s have almost half the risk of developing prostate cancer than men in their 70s [11]. It is also known that cancer incidence does not increase with age during the first years of life, probably because the incidence of some cancers (e.g., acute lymphoblastic leukemia, some cancers from the nervous system, liver cancer and kidney cancer) is higher during the first 5 years of life than during the following 20 years [11,12]. In addition, the incidence of some cancers (e.g., acute lymphoblastic leukemia, testicular cancer, cervical cancer, Hodgkin lymphoma, thyroid cancer, bone cancer, etc) does not increase exponentially with age within the age group 25-74 years [11,12]. For example, acute lymphoblastic leukemia incidence peaks during the first decade of life and testicular cancer incidence peaks during the third decade of life [11,12]. The somatic mutation theory does not explain why the accumulation of mutations occurring during a person's lifetime is not translated in many tissues into an increase in cancer incidence throughout life (Figure 1).

A

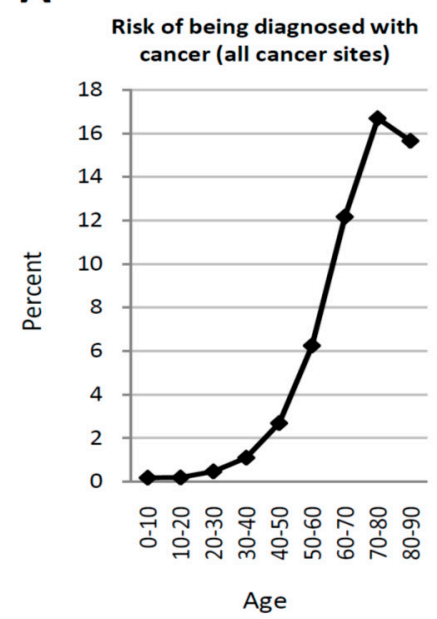

D

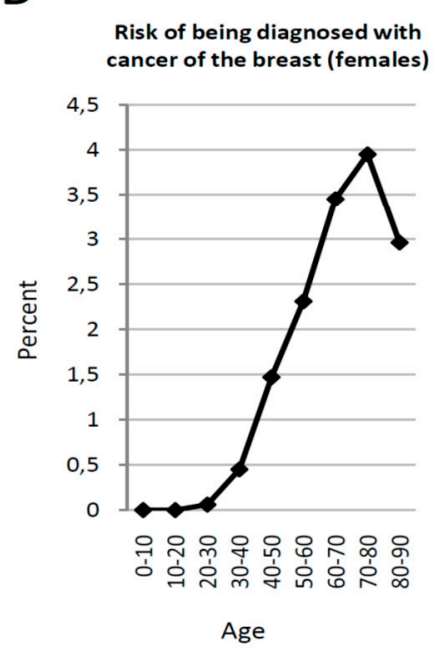

B

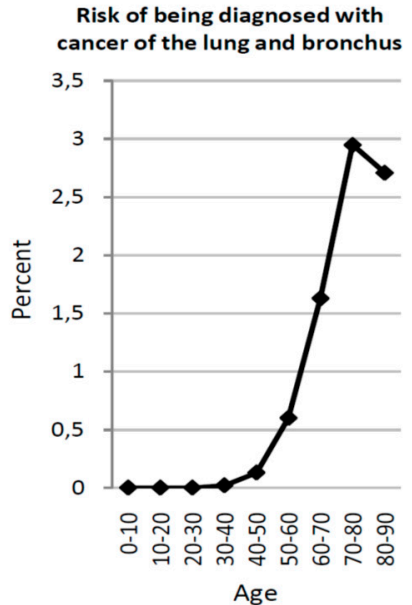

E

Risk of being diagnosed with cancer of the testis (males)

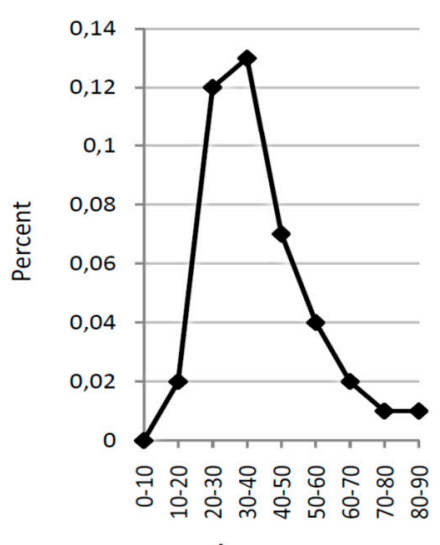

Age
C

Risk of being diagnosed with cancer of the prostate (males)

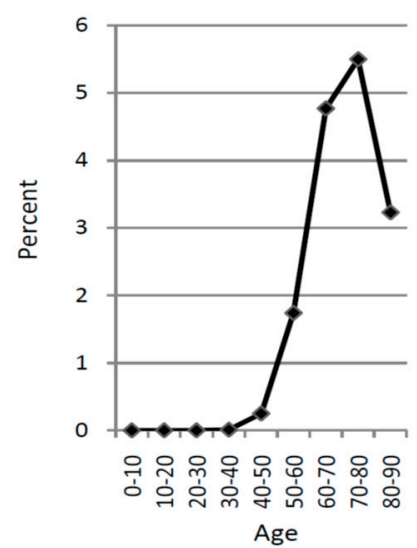

$\mathbf{F}$

Risk of being diagnosed with cancer (all cancer sites, 0-24 y)

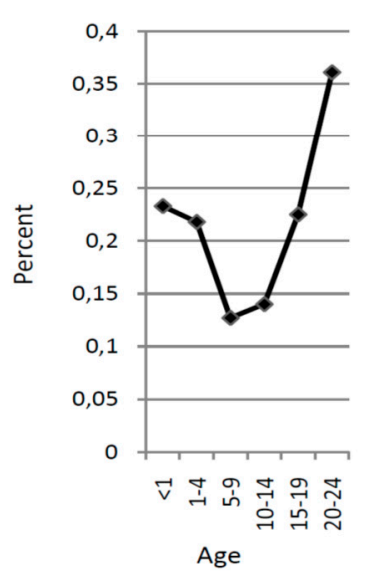

Figure 1. Cancer incidence by age. The risk of being diagnosed with cancer (A), or with one of the three most common cancers (B-D), increases dramatically with age. However, the risk decreases late in life for most cancers (e.g., A-D), and does not increase with age for some cancer types (e.g., E). In addition, cancer incidence does not increase with age during the first years of life (F). See text for further details. Data were taken from SEER cancer statistics review, 1975-2014 [11]. 
Second, if cancer is caused by gene mutations (permanent alterations in the nucleotide sequence in protein-coding DNA), all cancers would have mutations in genes. However, sequencing studies have found zero mutations in the genes of many tumor samples [13-16]. For example, Greenman et al. [14] reported 73 out of 210 tumors with zero mutations in protein-coding DNA sequences. Whole-genome and whole-exome sequencing of 47 ependymomas revealed an extremely low mutation rate, with zero significant recurrent nucleotide variants $[15,16]$. These data indicate that mutations in oncogenes and tumor-suppressor genes are not necessary for the formation of a variable proportion of different cancer types; this is also a major barrier to accept the somatic mutation theory.

Finally, the somatic mutation theory cannot easily accommodate epidemiological and experimental data showing that cancer risk and development are affected by multiple non-mutagenic factors. Human studies indicate that the risk of cancer is increased by hormone therapy (several cancer types) [17-19], shift work that involves circadian disruption (breast cancer) [20-23], drinking very hot beverages (esophageal cancer) [24-27] and exposure to non-ionizing electromagnetic fields (childhood leukemia) [28-34]. Carcinogenesis experiments in rodents have also shown that non-mutagenic factors can have a major impact on cancer incidence and development [13]. For example, surgical interruption of the sympathetic nervous system prevents the early phases of prostate tumor development [35], and denervation of the stomach suppresses all stages of gastric carcinogenesis [36]. If cancer is caused and driven by mutations, it is difficult to understand why drinking very hot beverages increases the risk of having esophageal cancer, or why cutting specific nerves suppresses the development of prostate and gastric cancer.

It is clear that carcinogenesis requires the multi-step accumulation of DNA changes. These DNA changes not only include mutations in genes, but also mutations in non-protein-coding DNA (which represents over $98 \%$ of the DNA), epigenetic alterations (DNA modifications that do not involve changes in the nucleotide sequence), and aneuploidy (numerical and structural abnormalities in chromosomes). All these DNA alterations have a marked effect on gene expression and are very common in cancer samples [37-41]. It is unclear, however, what causes these DNA changes, in what type of cell they take place, and if they are sufficient for cancer to occur.

Since carcinogenesis requires the multistep accumulation of DNA alterations, it is commonly assumed that cancer is primarily caused by exposure to DNA-damaging agents. If this were correct, cancer incidence would be rather similar in tissues exposed to similar levels of these agents. However, cancer registries show striking differences in cancer incidence among tissues, including those exposed to similar levels of DNAdamaging agents (Table 1). For example, the larynx and the lungs are exposed to tobacco smoke; however, lung cancer is much more common than larynx cancer. Although the small and the large intestines are exposed to dietary carcinogens, colorectal cancer occurs more frequently than small intestine cancer. Many DNA-damaging agents can enter the blood and reach all tissues, including the prostate and the heart. However, prostate cancer is over 100,000 times more frequently diagnosed than heart cancer (Table 1). It is unquestionable that many DNA-damaging agents increase the risk of cancer; tobacco use leads to the formation of DNA-damaging agents in our body, and lung cancer in heavy smokers is known to occur approximately 20 times more frequently than lung cancer in nonsmokers [42]. However, the striking differences in cancer incidence among tissues exposed to similar levels of DNA-damaging agents indicate that exposure to these agents is not the driving force of carcinogenesis.

\begin{tabular}{ll}
\hline Type of cancer & Lifetime risk \\
\hline Prostate cancer & $12.9 \%(\sim 1$ in 8 men $)$ \\
Breast cancer & $12.4 \%(\sim 1$ in 8 women $)$ \\
Lung and bronchus cancer & $6.5 \%(\sim 1$ in 15 people $)$ \\
Colorectal cancer & $4.4 \%(\sim 1$ in 23 people $)$ \\
Larynx cancer & $0.3 \%(\sim 1$ in 333 people $)$ \\
Small intestine cancer & $0.2 \%(\sim 1$ in 500 people $)$ \\
Bone and joint cancer & $0.1 \%(\sim 1$ in 1,000 people $)$ \\
Heart cancer & $0.00003 \%(\sim 1$ in $3,000,000$ people $)$ \\
\hline
\end{tabular}

Table 1. Risk of being diagnosed with cancer in selected tissues. Percent of people who will be diagnosed with specific cancer types at some point during their lifetime, based on Surveillance, Epidemiology and End-Results (SEER) Cancer Registry from 2011-2013 (https://seer.cancer.gov/statfacts/more.html). Data for heart cancer were obtained from reference [43]. 
After explaining several basic concepts in cell biology, this article reviews evidence that the driving force of carcinogenesis is the accumulation of cell divisions in stem cells [27,44-47]. This model of cancer provides an integrating framework for understanding carcinogenesis and has important implications for cancer prevention and therapy.

\section{Stem cells, progenitor cells, differentiated cells, differentiation and dedifferentiation}

All human cells can be classified into stem cells, progenitor cells and differentiated cells. Stem cells and progenitor cells constitute small populations specialized in producing cells, whereas differentiated cells make up the bulk of tissues and are specialized in a variety of functions other than producing cells. Both stem cells and progenitor cells can produce differentiated cells. However, only stem cells can self-renew and give rise to more stem cells [48-52]. This means that stem cells have the exclusive potential to produce an unlimited number of cells.

Stem cells carry out two essential biological functions: they hold and protect our DNA from zygote to death, and they divide to originate the huge number of cells [53] required to form and maintain our body tissues. Unfortunately, when stem cells divide to produce new cells, their DNA becomes exposed to mutations and other DNA alterations that can lead to stem cell exhaustion or cancer. In other words, stem cells should be quiescent to protect our DNA but have to divide to produce new cells. The existence of progenitor cells (commonly called transit-amplifying cells) partially solves this dilemma.

Stem cells directly produce all the cells at the initial stages of embryonic development; they divide symmetrically to increase the stem cell pool at the expense of accumulating cell divisions (Figure 2). But later, progenitor cells alleviate the accumulation of cell divisions in stem cells. At different moments in prenatal and postnatal life, stem cells divide to originate progenitor cells, which in turn divide a limited number of times to give rise to the differentiated cells that make up the bulk of tissues. If a stem cell divides asymmetrically to produce one stem cell and one progenitor cell and the progenitor cell divides ten times, one stem cell division will be sufficient to produce 1,024 differentiated cells. This hierarchy ensures the production of many differentiated cells while minimizing the accumulation of cell divisions and DNA alterations in stem cells. The risk of mutations associated with the last cell divisions required to produce differentiated cells is passed on to progenitor cells. However, since progenitor cells are programmed for terminal differentiation, the mutations acquired by progenitor cells will end up in differentiated cells. Differentiated cells rarely divide and are therefore less prone to accumulate additional mutations. In addition, these mutations are lost in many tissues when differentiated cells die to be replaced by new cells during tissue renewal. The mutations occurring in stem cells, however, can persist until death. Although most tissues follow a stem cell $\rightarrow$ progenitor cell $\rightarrow$ differentiated cell hierarchy, cell hierarchies are not identical in all tissues (see, e.g., reference [50]). 


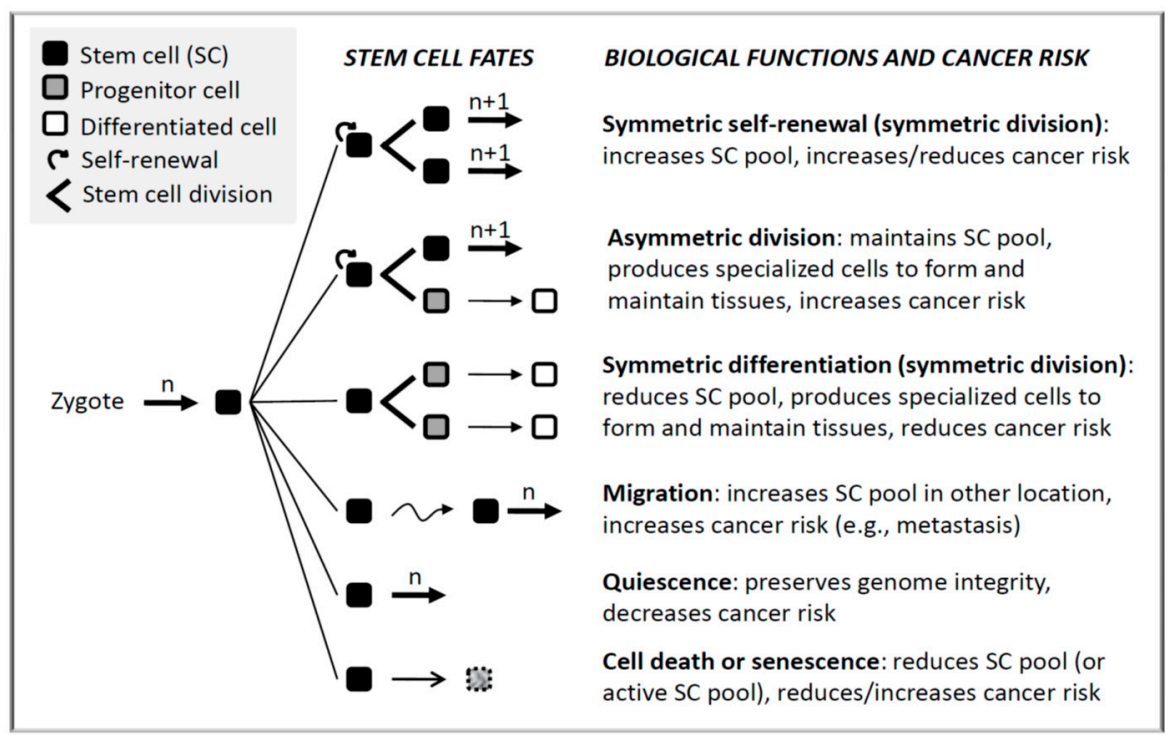

Figure 2. Stem cell fates, biological functions and cancer risk. Stem cells have two main biological functions: to preserve genome integrity and to produce via cell division the cells required to build and maintain body tissues. However, when stem cells divide to produce new cells, they become exposed to a variety of cancerpromoting errors (e.g., genetic alterations) that increase our risk of cancer. According to the stem cell division theory of cancer, the more cell divisions a stem cell has accumulated from the zygote, the higher its risk of malignant transformation. Increasing the stem cell pool (symmetric self-renewal) is an important strategy to prevent the accumulation of cell divisions in individual stem cells; if the number of cell divisions required for creating a given number cells is shared by many stem cells, none of them will accumulate an excessive number of cell divisions. However, an unnecessary increase in the stem cell pool can increase the risk of cancer, because there will be more targets for malignant transformation. There must be an equilibrium between the number of stem cells and the number of cell divisions accumulated by individual stem cells. If a stem cell differentiates symmetrically, remains quiescent, dies or enters senescence, its risk of becoming malignant decreases. However, its job has to be done by other stem cells, which will accumulate additional cell divisions. Linking stem cell fates to cancer risk is difficult. The key is to understand that cancer mainly occurs when one stem cell accumulates an excessive number of cell divisions, and that any change in stem cell fates inducing such an excessive number of cell divisions will increase our risk of cancer [47].

The term differentiation is difficult to define. The International Society for Stem Cell Research (ISSCR) defines differentiation as 'the process of development with an increase in the level of organization or complexity of a cell or tissue, accompanied with a more specialized function'. Cell differentiation is also defined as the process by which an unspecialized cell becomes specialized, or the process by which a less specialized cell becomes a more specialized cell. These definitions assume that producing cells is not a specialized function, or that producing cells is a function less specialized than other biological functions. In my opinion, cellular differentiation is the process by which cells specialized in producing cells progressively lose this capacity to become specialized in other functions. This process begins in the zygote and ends in a differentiated cell. The reverse process is called dedifferentiation. The last step in differentiation is called terminal differentiation, which generates cells with a stable cellular state. These cells are called differentiated cells or terminally differentiated cells.

Cell differentiation is an irreversible process in most cases. Otherwise, the mutations occurring in progenitor cells or differentiated cells would end up in stem cells, thereby facilitating their exhaustion or malignant transformation. Our life would also be at risk if our differentiated cells (e.g., neurons, cardiomyocytes) abandoned their normal functions to dedifferentiate and become other cells. In some situations, however, cell differentiation can be reversible [48-52]. Since most human cells have the same DNA (except some blood cells, gametes, etc), the shape and function of a cell largely depend on epigenetic modifications that determine which parts of the DNA are active or inactive. Each cell type is basically a different way of expressing our genome. Because epigenetic changes are reversible, any type of cell can potentially lose its identity and become any other type of cell (cellular plasticity). This has been demonstrated in the laboratory by cell manipulation. Transfer of a nucleus from a terminally differentiated cell into an 
enucleated egg cell results in epigenetic reprogramming leading to reestablishment of totipotency, which in turn can lead to the production of all the cells of an organism ("Dolly the sheep" was created with this technology) [54]. Overexpression of several transcription factors can also induce terminally differentiated cells to become pluripotent stem cells under artificial conditions [55]. Recent studies indicate that changes in cell identity are not limited to the laboratory; some non-stem cells have the capacity to dedifferentiate in response to tissue injury [51,56]. Non-stem cancer cells can also become cancer stem cells in vivo [57,58]. This implies that the DNA (and the DNA alterations) of progenitor cells and differentiated cells can return to stem cells under specific conditions.

Before explaining the stem cell division theory of cancer, it is important to clarify a basic concept in cell division and to define what a stem cell is. Cell division is a transformation process in which a mother cell duplicates and separates its cellular components to finally split into two daughter cells. Although the mother cell and the daughter cells often share similar properties, cell division transforms one cell into two new cells. Despite the nomenclature, cell division is not analogous to the process by which mothers give birth to daughters, because women continue to exist after giving birth to their children. This idea is important, because the assumption that the mother cell remains after cell division is a major source of confusion in the fields of stem cell biology and cancer. Stem cells should not be seen as cells that can divide many times. For example, a totipotent stem cell cannot divide many times because it no longer exists after several rounds of cell division (totipotent stem cells become pluripotent stem cells at the initial stages of embryonic development). Stem cells should be seen as cells that can produce many cells, or as cells whose DNA can undergo many cell divisions. A totipotent stem cell can initiate the production of all the cells of an organism, and the DNA of a totipotent stem cell can undergo cell divisions until the end of the life of an organism or tissue (e.g., extraembryonic tissues).

Currently, stem cells are defined as cells with self-renewal capacity and differentiation potential [48-52]. Because progenitor cells also have differentiation potential (ability to produce differentiated cells), it is widely accepted that the defining feature of stem cells is their self-renewal capacity. However, it is unclear what selfrenewal means. To most researchers, self-renewal is the ability of a cell to make an exact copy of itself by cell division, or the ability of a cell to produce daughter cells with the same properties of the original cell. However, not all stem cells meet these definitions, and some non-stem cells do. At some point in embryonic development, totipotent and pluripotent stem cells can no longer make copies of themselves. They produce adult stem cells (also called tissue stem cells), which have different properties from embryonic stem cells (they produce less types of cells than embryonic stem cells). Under specific liver damage conditions, hepatocytes can divide and produce two daughter cells with the same properties of the original cell [59]; hepatocytes would have self-renewal capacity according to these definitions. Self-renewal has also been defined as ability to go through numerous cycles of cell division while maintaining the undifferentiated state. As mentioned previously, however, totipotent stem cells cannot go through numerous cycles of cell division because they no longer exist after several cycles of cell division. In addition, some progenitor cells can go through several cycles of cell division while maintaining the undifferentiated state, and terms such as numerous and several denote imprecision and should be avoided in a definition. Finally, self-renewal has been defined as ability to make more stem cells. For example, the International Society for Stem Cell Research defines stem cells as 'cells that have both the capacity to self-renew (make more stem cells by cell division) as well as to differentiate into mature, specialized cells'. Defining stem cells is so challenging that the term introduced to describe the defining feature of stem cells (self-renewal) cannot be accurately explained without coming back to the term stem cell. Defining stem cells as cells that can make more stem cells is correct but evasive; it is like defining bacteria as organisms that can make more bacteria.

In my opinion, a stem cell is a cell with the potential to produce an unlimited number of cells. In vivo, this potential is restricted by the lifespan of the organism or tissue where it resides. A stem cell can also be defined as a cell whose DNA has the potential to go through an unlimited number of cell divisions under permissive extracellular conditions. All and only stem cells meet these definitions, including totipotent stem cells, pluripotent stem cells, extraembryonic stem cells (e.g., umbilical cord stem cells), and all types of tissue stem cells (multipotent, bipotent, and unipotent). A summary of the defining features and main biological functions of stem cells, progenitor cells and differentiated cell is shown in Figure 3. 


\section{STEM CELLS}

- Cells specialized in producing cells. They can produce more stem cells (self-renewal ability) and differentiated cells (differentiation potential).

- They have the potential to produce an unlimited number of cells until the end of the life of an organism or tissue; their DNA can go through an unlimited number of cell divisions.

- They can hold and transmit our DNA from zygote to death. The DNA alterations occurring in stem cells can persist throughout life.

- Their main mission is to store and protect our genetic material throughout life and to drive the production of the large number of cells required for living.

\section{PROGENITOR CELLS (TRANSIT-AMPLIFYING CELLS)}

- Cells specialized in producing differentiated cells; they have differentiation potential.

- They cannot produce an unlimited number of cells; they are programmed to go through a limited number of cell divisions and then become differentiated cells.

- They transmit the DNA stored in stem cells to differentiated cells. They usually are short-lived and hold our DNA temporarily, especially in tissues that renew their cells frequently.

- Their main mission is to prevent stem cells from accumulating an excessive number of cell divisions, which could lead to stem cell exhaustion or cancer.

\section{DIFFERENTIATED CELLS}

- Cells specialized in a variety of body functions other than producing cells.

- They rarely divide.

- They are long-lived in tissues that do not renew their cells frequently and short-lived in tissues that renew their cells regularly. The DNA alterations transmitted by progenitor cells, or occurring in differentiated cells, are eliminated during tissue renewal.

- Their main mission is to carry out most body functions.

Figure 3. Stem cells, progenitor cells and differentiated cells. All human cells can be classified into stem cells, progenitor cells and differentiated cells. This figure shows the defining features and main biological functions of these cells. See text for details.

\section{The stem cell division theory of cancer (SCDTC)}

\subsection{The cellular origin of cancer}

Although it is accepted that carcinogenesis requires the multi-step accumulation of DNA alterations, it is unclear in what type of cells these DNA alterations accumulate [60-62]. Currently, experimental data suggest that some cancers originate in stem cells and others in non-stem cells. For some common cancers, different experimental approaches have led to the identification of different cells of origin for cancer [60-66].

The strategies used to identify the cells of origin in cancer usually consist of activating oncogenes and/or inactivating tumor suppressor genes in different cell populations, and then evaluate their tumorigenic potential in mice [60,61]. For example, because MYC amplification and PTEN loss are commonly detected in prostate cancers, the authors of a recent article [66] transduced primary human prostate basal and luminal cells with lentiviruses expressing c-Myc and activated AKT1 to mimic MYC amplification and PTEN inhibition. After propagation in organoid culture, the cells formed subcutaneous tumors in immunodeficient mice. The authors proposed that prostate cancers arise from both cell types, and that the distinct subtypes of prostate cancer may arise depending on which of these cells serves as the cell of origin of cancer [66].

The strategies used to identify the cellular origin of cancer, however, rely on a variety of assumptions and experimental manipulation that may have led to wrong conclusions. The following analogy, based on the study mentioned above [66], may be useful to draw attention to the limitations of these strategies. Consider that we are investigating traffic accidents (prostate cancers) involving several vehicles (cell types) to identify which one causes the accidents (cell of origin in cancer). We find numerous injuries (DNA alterations) in drivers and passengers in most accident scenarios. However, since many drivers have broken ribs (MYC amplifications and PTEN losses), we consider that these injuries play a causal role in the accidents. To determine which type of vehicle causes the collisions, we focus on cars and vans (basal and luminal cells). We recruit two volunteers to drive a car and a van through a road in which we have created artificial conditions (organoid culture and immunodeficient mice). After breaking two ribs (MYC and PTEN) of each driver, both vehicles eventually cause a traffic accident. We conclude that traffic accidents are originated in cars and vans. 
We cannot demonstrate experimentally what cell type acquires the first carcinogenic hit. We would have to know what the first hit is, and it is virtually impossible to analyze a tumor sample or premalignant lesion and determine which of the thousands of DNA changes found there [8,67] occurred first. In addition, since carcinogenesis is stochastic in nature, the first cancer-related change may be different in people with the same type of cancer. Furthermore, many DNA alterations found in tumor samples probably are a consequence of carcinogenesis rather than a cause [68,69], like broken ribs are usually a consequence of traffic accidents rather than a cause. Finally, the cells used in the experiments to identify the cellular origin of cancer are genetically and chemically manipulated and often taken away from their natural environments. Experimental approaches with these assumptions and experimental manipulations may lead to wrong conclusions.

An alternative strategy to identify the cellular origin of cancer is to analyze the striking differences in cancer incidence by age and among tissues using basic concepts in cell biology. As discussed previously, the dramatic increase in cancer incidence with age indicates that the formation of most cancers requires the multistep accumulation of DNA changes over years or decades. If cancer were caused by only one cellular change, or by several changes occurring simultaneously or in a short period of time, these changes could occur at any moment in life, and cancer incidence would be rather similar in different age groups after a latency period. This implies that the cells of origin in cancer must be able to hold our DNA during years or decades. Importantly, stem cells carry our DNA from zygote to death and can therefore hold our DNA long enough to accumulate the DNA alterations required for carcinogenesis. In tissues with a low capacity to renew their cells (e.g., heart tissue), non-stem cells are long-lived and can accumulate DNA alterations during decades. However, cancer rarely arises from these tissues [43] (Table 1). Cancer registries show that most cancers arise from tissues that renew their cells frequently. In these tissues, stem cells periodically pass a copy of our DNA to progenitor cells (transit amplifying cells), which in turn pass it to the differentiated cells that form the bulk of tissues. However, these DNA copies and the mutations they bear are eliminated when differentiated cells die to be replaced by new cells. This means that the progenitor cells and differentiated cells of the tissues from which most cancers arise do not hold our DNA long enough to accumulate the DNA alterations required for carcinogenesis. This indicates that, in most cancer cases, carcinogenesis develops in stem cells.

Additional evidence indicates that cancer originates in stem cells. Stem cells constitute the only cell population at the initial stages of embryonic development and, therefore, they are the only cells that can acquire cancer-related changes during this period of intense mitotic activity. Cell division is an important source of DNA alterations; for example, it has been estimated that three mutations occur every time a normal stem cell divides [70,71]. If cancer originated in non-stem cells, our DNA would have to go through numerous cycles of cell division in stem cells without acquiring any cancer-related DNA change. Then, after acquiring a DNA alteration in a progenitor cell or differentiated cell, the cell would have to dedifferentiate into a stem cell to prevent the DNA alteration from being lost during tissue renewal. In addition, if cancer originated in non-stem cells that then dedifferentiate into stem cells [62], the progenitor cells or differentiated cells created, e.g., at age 10 would have the same probability of acquiring the first cancer-related change than those created at age 30 or 50. After a latency period of e.g. 20 years, cancer incidence would be rather similar at ages 30, 50 and 70. This is incompatible with cancer statistics by age observed in all cancer registries (Figure 4). For example, the average number of new cases of prostate cancer per year in the United Kingdom was 46,452 for the 2012-2014 period; however, only 6 cases per year were diagnosed in men in their 30 s, 4,747 in men in their 50s and 16,524 in men in their 70s [12]. 
A

\section{Risk of being diagnosed with} cancer (all cancer sites)

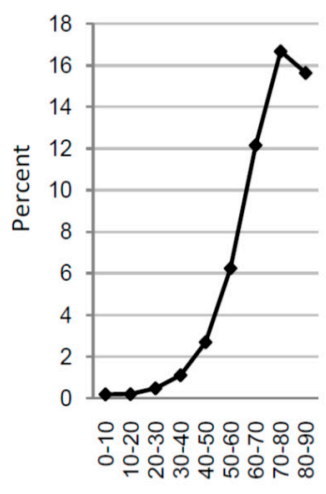

Age
B

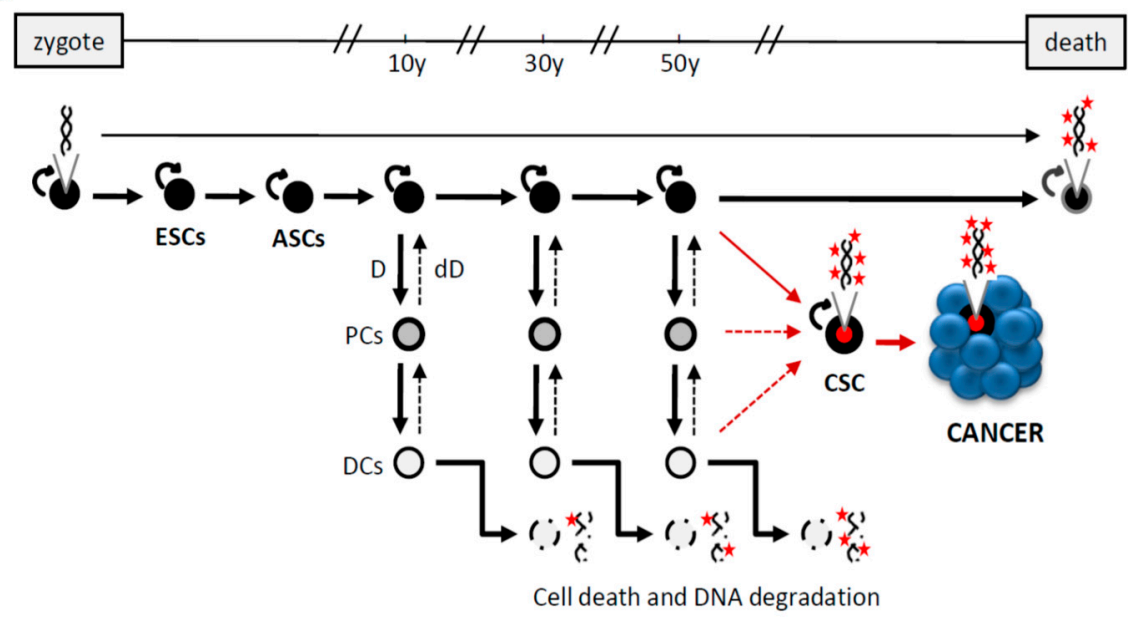

Figure 4. The cellular origin of cancer. The dramatic increase in cancer incidence with age (A) indicates that the formation of most cancers requires the multistep accumulation of cellular changes over years or decades (if cancer were caused by only one cellular change, this change could occur at any moment in life and cancer incidence would be rather similar at different ages). Importantly, DNA is the only cellular component that can accumulate changes throughout life, and stem cells are the only cells that can keep our DNA from zygote to death (B). This means that stem cells can accumulate the cellular changes required for carcinogenesis. At different moments in life, stem cells pass a copy of our DNA to progenitor cells, which in turn pass it to differentiated cells. However, these DNA copies are degraded when differentiated cells die to be replaced by new cells during tissue renewal. If cancer originated in progenitor cells or differentiated cells, those created at age 10,30 or 50 would have the same probability of acquiring the first cancer-related change. After a period of e.g. 20 years (during which the cell would acquire the rest of the cancer-related changes required for carcinogenesis), cancer incidence would be rather similar at ages 30,50 or 70. This is incompatible with cancer statistics shown in panel $\mathbf{A}$. Therefore, the marked increase in cancer incidence with age indicates that most, if not all, cancers originate and largely develop in stem cells [47,72]. Curved arrows represent self-renewal capacity. Broken arrows represent less-common pathways. Stars represent DNA alterations. Non-stem tumor cells are represented in blue. ESCs: embryonic stem cells; ASCs: adult stem cells; CSC: cancer stem cell; PCs: progenitor cells; DCs: differentiated cells; D:differentiation; dD: dedifferentiation.

It is unlikely that the DNA alterations required for cancer formation take place in only one cell or cell type. Some DNA alterations probably occur in embryonic stem cells, others in adult stem cells and others in cancer stem cells (CSCs). CSCs are cells that can produce an unlimited number of cancer cells. Also called tumor-initiating cells in solid tumors, CSCs are responsible for initiating and maintaining cancer growth. In some cases (e.g., after tissue injury), the DNA alterations occurring in progenitor cells or differentiated cells can enter the stem cell pool after a dedifferentiation process and can therefore participate in carcinogenesis. The DNA alterations occurring in non-stem cancer cells can come back to CSCs if they dedifferentiate; cancer cells have a high cellular plasticity [57,73]. The accumulation of DNA alterations occurring during the division of CSCs leads to tumor heterogeneity and probably to cancer aggressiveness and drug resistance. Since carcinogenesis is stochastic in nature, it may be impossible to analyze a cancer sample and determine what cells or cell types acquired the DNA alterations required for the formation of that cancer. However, the striking differences in cancer incidence by age and among tissues strongly suggest that, in most cancer cases, the DNA alterations required for carcinogenesis originate and largely develop in stem cells (Figure 4).

\subsection{The main biological cause of cancer}

It has been known for many years that cancer arises much more frequently from some tissues than from others (Table 1). Because most primary tumors develop in tissues that renew their cells regularly, it has long been suspected that the number of cell divisions occurring in a tissue is crucial for carcinogenesis. Three recent articles strongly support this idea [74-76]. In the first article, Tomasetti and Vogelstein [74] reported a highly positive correlation between the lifetime number of stem cell divisions occurring in 31 tissues and the 
risk of being diagnosed with cancer in those tissues. The correlation was striking (Spearman's rho $=0.81 ; P<$ $3.5 \times 10^{-8}$ ). It extended across five orders of magnitude, thereby applying to cancers with enormous differences in incidence. Wu et al. [75] also observed a high correlation (0.75) between the total number of all cell divisions in a tissue and the risk of cancer in the tissue. Both studies were confined to the U.S. population [74,75]. More recently, Tomasetti et al. [76] confirmed that the striking correlation between the lifetime number of stem cell divisions in a tissue and the risk of cancer in that tissue was similar $($ median $=0.80)$ in 69 countries representing over half of the world's population. However, these findings were used to estimate the proportion of cancers that can be prevented [74-76], and to propose that two-thirds of the mutations required for cancer are caused by unavoidable errors arising during DNA replication [74,76]. In my opinion, these data involving thousands of millions of people around the world provide definitive evidence that the main biological cause of cancer is the accumulation of cell divisions in our cells.

The striking correlation reported by Tomasetti et al. [74,76] indicates that if one of our tissues accumulates a number of stem cell divisions thousands of times higher than other tissue, the probability of having cancer in the first tissue is thousands of times higher than the probability of having cancer in the second tissue. This can explain, for example, why colon cancer is about 100,000 times more frequently diagnosed than heart cancer (Table 1). Because a person is made up of tissues, this striking correlation indicates that the main biological cause of cancer is the number of stem cell divisions accumulated during a person's lifetime.

As discussed previously, the dramatic increase in cancer incidence with age indicates that carcinogenesis is a multistep process that requires the gradual accumulation of DNA changes. This implies that the number of cell divisions accumulated by the cells of a tissue is more relevant for carcinogenesis than the total number of cell divisions accumulated by the tissue. In simple terms, the probability of accumulating the multiple DNA alterations required for carcinogenesis will be higher if 1 cell accumulates 15 cell divisions than if 3 cells accumulate 5 cell divisions each. The following experiment may be useful to reinforce this key concept. Consider that stem cells are dices, that each time a stem cell divides a dice is rolled, that the number obtained represents the risk of cancer, and that a stem cell gives rise to cancer when the sum reaches 30 . If you have 1 dice and roll it 15 times, the probability of reaching 30 is very high (99.99\%). However, if you have 3 dices and roll each of them 5 times in 3 independent experiments ( 15 dice roles in total), the probability of reaching 30 with any of the 3 dices is very low $(0.01+0.01+0.01=0.03 \%)$ [47]. Naturally, the risk of cancer will also increase if the number of cells accumulating cell divisions increases (the risk will be higher if 3 stem cells accumulate 15 cell divisions each than if only 1 stem cell accumulates 15 cell divisions), because there will be more targets for malignant transformation. Therefore, the highly positive correlation between the lifetime number of stem cell divisions in a tissue and the incidence of cancer in that tissue [74,76], together with the striking increase in cancer incidence with age, indicates that the main biological cause of cancer is the number of cell divisions accumulated by the stem cells of our tissues rather than the total number of stem cell divisions accumulated by the tissues. Unfortunately, stem cell hierarchies in most tissues are not yet sufficiently defined [50] to demonstrate this logical statement.

Our cells start accumulating cell divisions when our biological life starts, that is, from the zygote. Although Tomasetti et al. [74,76] did not consider the stem cell divisions occurring from zygote to birth, the lifetime number of cell divisions accumulated by our stem cells starts counting from the zygote. In addition, the DNA of stem cells can have accumulated cell divisions in different types of cells, including totipotent stem cells, pluripotent stem cells, adult stem cells and even in non-stem cells that dedifferentiate into stem cells, e.g., after tissue injury (Figure 4). This indicates that the main determinant of carcinogenesis is the number of cell divisions that the DNA of a stem cell has accumulated in any type of cell from the zygote. The more cell divisions a stem cell has accumulated from the zygote, the higher the probability that the stem cell will divide uncontrollably to form a cancer.

The accumulation of cell divisions in a cell is crucial for carcinogenesis because cell division can lead to a variety of cancer-related errors. Cell division can generate spontaneous mutations arising during DNA replication [70,71]. Cell division can also generate chromosome aberrations occurring during mitosis [77-81]; chromosome segregation errors can lead to mutations and chromosome rearrangements that integrate into the genome [78,79]. These DNA alterations can affect important genes (e.g., oncogenes and tumor-suppressor genes) and disorder genetic programs controlling stem cell behavior and fate. Cell division can also lead to failures in the distribution of cell-fate determinants between the daughter cells. The differential partitioning of 
cell fate determinants (e.g., transcription factors and mRNAs) between the daughter cells is known to induce changes in cell behavior and fate [82-86]. Errors in the distribution of cell fate determinants can disrupt the balance between symmetric and asymmetric cell division $[82,83,87,88]$, which can lead to the accumulation of cell divisions in stem cells (Figure 2). Cell division can also lead to failures to restore physical interactions with other tissue components. The division of stem cells is controlled by many extracellular factors, including physical interactions with the cellular and non-cellular components forming the anatomical location of stem cells [89-94]. These physical interactions are known to restrain cell division; the inhibitory effect of cell-cell contact on cell division has been known for many years and has been implicated in malignancy [95-100]. Many of these physical interactions are broken during cell division (see, e.g., https://www.youtube.com/watch?v=tc5bREsl8go). If a daughter cell fails to recover these interactions after cell division, the cell may be unable to come back to a resting state and may continue to divide. Detached cells may also migrate to other locations, which may be more permissive for cell division. Although some errors occurring during cell division do not directly cause DNA alterations, any error promoting the accumulation of an extra number of cell divisions in a cell will lead to the accumulation of an extra number of DNA alterations in the cell, because cell division inevitably generates DNA alterations [70,71]. But the carcinogenic potential of cell division is not only limited to the generation of DNA alterations. As mentioned above, each time a cell divides, the physical interactions that restrict cell division are temporarily broken. This demands both the cell and the neighboring cellular and non-cellular tissue components to be fit enough to cooperate in the recovery of these interactions to regain control of cell division. In addition, we cannot forget that cell division is mandatory for the formation and growth of the abnormal cell populations that characterize the disease.

Cell division is also important for carcinogenesis because it exposes the DNA of the cell to the genotoxic activity of DNA-damaging agents. The DNA of dividing cells is more vulnerable to genotoxic agents than the DNA of non-dividing cells. During cellular quiescence, the DNA is less accessible to genotoxic agents because it is highly packaged into chromatin and also because it is protected by the nuclear membrane. When the cell divides, the DNA unwinds to be copied during DNA replication and the nuclear envelope disappears during mitosis; these cellular events facilitate the interaction of DNA-damaging agents with the DNA of the cell.

In addition, cell division is important for carcinogenesis because it amplifies the DNA damages occurring during quiescence. The DNA of our cells has limited chemical stability and is constantly under attack [101]. It has been estimated that, on average, tens of thousands of DNA damages occur per day per cell in humans mainly due to hydrolytic reactions (e.g., depurinations and cytosine deaminations) and to reactive molecules produced by metabolism (e.g., reactive oxygen species) [101-103]. Although most of these naturally-occurring DNA damages are repaired, others escape repair and accumulate in our cells. The formation of these DNA damages does not require cell division. However, the fact that cancer almost never originates in tissues whose cells rarely divide indicates that these endogenous DNA damages do not play a major role in carcinogenesis in the absence of cell division. Cell division probably transforms these relatively innocuous DNA damages (e.g., oxidative damage) into more dangerous DNA alterations (e.g., mutations) [104,105]. For example, the common oxidative lesion 8-oxoguanine (also called 8-hydroxyguanine) promotes the mispairing potential of DNA polymerases and increase mutation frequency [104]. In the presence of cell division, naturally-occurring DNA damage may be crucial for carcinogenesis, and probably the origin of many DNA alterations required for the development of the disease. The high incidence of naturally-occurring DNA damage in our cells might actually explain the different sets of mutations found in different cancer types. The spontaneous mutations arising when DNA polymerases misread undamaged DNA sequences [106] does not explain the singular mutational load found in different cancer types. If most mutations occur spontaneously when our whole genome is copied during cell division, polymerases could make mistakes in any region of the genome, and the mutation pattern would be rather similar in different tissues and cancers. The high prevalence of naturally-occurring DNA damage in our cells may explain these different mutation patterns. As discussed previously, virtually all the cells of a person have the same genome, and the shape and function of each cell basically depend on which parts of the DNA are active or inactive. Inactive parts of the DNA are usually packaged into chromatin structures, which provide a strong protection against DNA damage, e.g., oxidative DNA damage [107]. Although cells need to use housekeeping genes [108], different tissues also need to express different sets of genes to carry out specific functions. The activation of a particular genetic program requires accessibility to specific genes and non-coding DNA regulatory sequences so that 
transcription can occur. DNA accessibility, however, facilitates the interaction between these specific DNA sequences and DNA-damaging agents. DNA damage occurring in these particular sequences can be transformed into specific mutations during cell division. Since different tissues expose different sets of genes, they can have different sets of mutations. For example, mutations of the BRAF gene are very common in melanoma, possibly because a principal melanocyte-specific signaling pathway controlling proliferation and differentiation operates through activation of this gene [109]. Naturally, many other factors are involved, including the exposure frequency of the DNA sequence, the type and levels of endogenous and exogenous DNA-damaging agents present in the tissue, the DNA repair capacity of the tissue, the number of cell divisions occurring in the cells of the tissue, etc.

Cell division can also amplify DNA damage caused by environmental carcinogens. For example, if a cell is exposed to ultraviolet (UV) radiation during quiescence, the cell will acquire DNA damages that will increase the amount of mutations occurring during DNA replication. DNA polymerases will insert more wrong nucleotides during DNA replication if they find UV-induced pyrimidine dimers in the DNA they are replicating than if they do not find these DNA damages [110,111]. Some errors arising during cell division are unavoidable, but others are influenced by environmental factors.

\begin{tabular}{|c|c|}
\hline $\begin{array}{l}\text { CARCINOGENIC POTENTIAL OF CELL } \\
\text { DIVISION } \\
\text { - Mutations arising during DNA replication. } \\
\text { - Chromosome alterations occurring during mitosis. } \\
\text { - Amplification of naturally-occurring DNA damage } \\
\text { acquired during quiescence. } \\
\text { - Amplification of DNA damage induced by } \\
\text { environmental carcinogens. } \\
\text { - Facilitate the interaction between DNA-damaging } \\
\text { agents and the DNA of the cell. } \\
\text { - Failures in the distribution of cell-fate } \\
\text { determinants between the daughter cells. } \\
\text { - Temporal loss of physical interactions with other } \\
\text { tissue components that restrain cell division. } \\
\text { - Cell division generates the cells required for tumor } \\
\text { formation and growth. }\end{array}$ & $\begin{array}{l}\text { HUMAN EVIDENCE THAT CELL DIVISION IS } \\
\text { THE KEY EVENT IN CARCINOGENESIS } \\
\text { - Most cancers originate in self-renewing tissues, } \\
\text { that is, in tissues that accumulate many cell } \\
\text { divisions. } \\
\text { - Cancer almost never arises from tissues } \\
\text { composed of cells that rarely divide, even though } \\
\text { these tissues and cells are also exposed to } \\
\text { naturally-occurring DNA damage and to } \\
\text { environmental carcinogens. } \\
\text { - Cancer incidence increases dramatically with age } \\
\text { in tissues that accumulate cell divisions with age. } \\
\text { - Highly positive correlation between the number } \\
\text { of (stem) cell divisions accumulated by a tissue } \\
\text { during a person's lifetime and the number of } \\
\text { cancers occurring in that tissue. }\end{array}$ \\
\hline
\end{tabular}

Figure 5. Key role of cell division in cancer. The left panel shows mechanisms by which cell division leads to cancer. The right panel shows evidence that cell division is the key event in carcinogenesis; all this evidence is based on human studies involving millions of people around the world (see text for details).

The accumulation of cell divisions occurring at the initial stages of carcinogenesis is primarily caused by multiple physiological signals rather than by errors in the DNA of the dividing cell. These physiological signals are necessary to drive the process by which one cell (zygote) gives rise through cell division to the huge number of cells required for living. Naturally, the accumulation of cell divisions needed for this process does not require mutations. The mutations arising during this process [9] are a consequence, not a cause, of the accumulation of cell divisions in our cells. Numerous pathological and environmental factors (e.g., tissue injury, infections, inflammation, and exposure to mitogenic agents or cytotoxic factors) can trigger additional cell divisions, which will add to the number of cell divisions resulting from physiological factors. The accumulation of cell divisions in stem cells leads to the accumulation of mutations and other DNA alterations. Some of these DNA changes deregulate genetic programs controlling stem cell behavior and fate. At some point in carcinogenesis, these genetic alterations promote cell division and can even trigger cell division under permissive extracellular environments. These extra cell divisions lead to the accumulation of additional DNA alterations, which in turn promote the accumulation of additional cell divisions. This vicious circle drives the malignant transformation of the cell and the production of the abnormal cell populations that characterize cancer. 
The accumulation of DNA alterations in a cell is not sufficient for cancer to occur. It is widely accepted that if a cell accumulates specific mutations, epigenetic alterations and/or chromosome aberrations, the cell will proliferate uncontrollably and will give rise to a cancer. It is unquestionable that the accumulation of DNA alterations is necessary for cancer to occur; DNA is the only cellular component that can accumulate and transmit the cellular changes required for carcinogenesis. However, the accumulation of DNA alterations in a cell is not sufficient for cell division and cancer formation. This affirmation can be easily tested by culturing any type of cancer cell in a solution of PBS. Although the cells will remain viable for some time, they will not proliferate during this time despite their DNA alterations. The reason is that cell proliferation not only requires DNA changes permissive for cell division. Cell proliferation also requires that the dividing cell takes up nutrients (e.g., glucose and amino acids) from the extracellular environment; these nutrients provide the building blocks required for the synthesis of the components needed to create a new cell [112,113]. But even if the cancer cells are placed in a culture medium containing all the nutrients required for the production of new cells, cell proliferation will be inhibited unless the medium is supplemented with specific hormones and growth factors (generally provided by fetal bovine serum) [114,115]. Cancer formation requires the production of new cells through cell division, and cell division will not occur unless the cell receives specific nutrients and signals from the extracellular environment.

Realizing that the accumulation of DNA alterations in a cell is not sufficient for cancer to occur is important for understanding, for example, why the lifetime accumulation of mutations in the cells of our tissues is not translated into an increase in cancer incidence throughout life (see Figure 1). It is well known that the stem cells of different tissues respond to different mitogenic signals, and that the levels of many of these signals (e.g., growth hormone, insulin-like growth factor 1, testosterone, estradiol, anti-mullerian hormone, etc) change at specific moments in life. The changing cocktail of mitogenic signals occurring throughout life causes that the stem cells of some tissues stop responding to these signals at different moments in life. For example, our bones do not continue to grow once growth hormone levels decline below certain levels at age 15-20 (other signals are also involved). Bone cancer incidence increases until that age, but then decreases and stabilizes [11,12]. Prostate and breast cancer incidence decrease late in life probably because the steady decline in testosterone and estradiol levels starting after midlife may drop below a threshold required to stimulate the division of the cells of these tissues. The drastic changes in hormone levels occurring during male puberty in the hypothalamic-pituitary-testicular axis [116] may explain why testicular cancer incidence peaks 1-2 decades later (Figure 1). According to the stem cell division theory, cancer incidence increases dramatically with age because the stem cells of many tissues accumulate cell divisions with age. As we progress from zygote to death, our stem cells accumulate cell divisions, DNA alterations and cancer risk. However, the transformation of a normal cell into a cancer cell requires cell division, and the accumulation of DNA alterations in a cell will not lead to cell division unless the extracellular cocktail of mitogenic signals (chemical and physical signals) is permissive for cell division. The accumulation of mutations in driver genes does not ensure cell division and cancer formation.

Carcinogenesis requires the accumulation of cell divisions and DNA alterations in a cell. Cancer will not occur if the cell does not develop mutations and/or other DNA changes. Cancer will neither occur if the cell does not divide. Both events promote each other and form the vicious circle that drives carcinogenesis. Since both events are necessary for carcinogenesis, any of them could be considered as the main biological cause of cancer. However, the accumulation of DNA alterations in a cell is not sufficient for cancer to occur, whereas the accumulation of cell divisions in stem cells is sufficient for cancer formation. The accumulation of cell divisions in stem cells drives not only the accumulation of the DNA alterations required for carcinogenesis, but also the formation and growth of the abnormal cell populations required for cancer formation. In addition, there is a striking association between the incidence of cancer in a tissue and the lifetime accumulation of stem cell divisions in the tissue [74,76], but not between the incidence of cancer in a tissue and the lifetime accumulation of mutations in the tissue [10]. Taken together, the evidence strongly suggests that the main biological cause of cancer is the accumulation of cell divisions in stem cells rather than the accumulation of DNA alterations in a cell. 


\subsection{The stem cell environment plays a key role in carcinogenesis}

If cancer is the end-result of the accumulation of cell divisions in stem cells, it is crucial to understand what causes the cell divisions required for carcinogenesis. This section discusses that these cell divisions are not only caused by DNA alterations occurring inside the cells that give rise to cancer, but also by a variety of extracellular factors that can be grouped in the term 'stem cell environment'. Understanding carcinogenesis requires understanding how the stem cell environment controls and alters stem cell behavior and fate.

Stem cells are not independent organisms that decide when to divide. Stem cells serve the needs of an organism that control their behavior and fate in response to changes occurring inside and outside it. The stem cell environment comprises a variety of local, systemic and environmental factors that control stem cell quiescence, self-renewal, differentiation, migration, survival and death. The term stem cell environment is broader than the terms microenvironment or stem cell niche [117,118]. The stem cell environment includes the cellular and non-cellular components forming the anatomical location of the stem cell. It also comprises chemical and physical signals acting on the stem cell (e.g., hormones, growth factors, cytokines, signals from the nervous system, and local mechanical and electrical signals) [117-119]. It also includes the extracellular levels of nutrients (macronutrients and micronutrients), oxygen, protons $(\mathrm{pH})$ and other ions (e.g., $\mathrm{Na}^{+}$and $\mathrm{K}^{+}$), because stem cell behavior and fate is influenced by physiological changes in these parameters [8894,96,120-124]. The stem cell environment also includes any cell from any part of the body that produces any signal, cell, or non-cellular component controlling stem cell behavior or fate [47]. For example, the division of epithelial stem cells is influenced by their physical interactions with the collagen fibers forming the extracellular matrix $[121,125,126]$. Since these collagen fibers are produced by fibroblasts, the accumulation of DNA alterations in fibroblasts (e.g., mutations in the collagen genes), or in the cells that gave rise to the fibroblasts, can affect the division rates of the epithelial stem cell. Likewise, some cells of the adenohypophysis and testicles form part of the environment of prostate stem cells, because they produce hormones (e.g., luteinizing hormone and testosterone) that regulate their behavior. By eliminating testicular cells, castration reduces the levels of testosterone and prevents prostate cancer development in some patients [127]. Sympathetic and parasympathetic nerves are part of the environment of specific stem cells because the activity of these nerves influences their behavior $[36,117,121]$. Denervation of the stomach suppresses gastric carcinogenesis probably because the parasympathetic vagus nerve facilitates carcinogenesis by promoting the division of the stem cells of the stomach [36]. The stem cell environment of any stem cell actually includes any signal generated inside or outside the body that the nervous system receives and traduces into any message (e.g., changes in hormone and neurotransmitter levels) affecting the behavior of the stem cell. Light is part of the environment of some stem cells because it can affect their behavior $[128,129]$. This can explain why circadian disruption from electric lighting can increase the risk of cancer, particularly breast cancer [2022,130-132]. Shift-work that involves circadian disruption is actually classified by the International Agency for Research on Cancer as probably carcinogenic to humans (Group 2A) [23]. The microbiota is part of the stem cell environment because it can affect stem cell behavior and fate in a variety of ways (e.g., production of chemicals, consumption and production of macronutrients and micronutrients, immunomodulatory effects, etc); this can explain why changes in the microbiota alter cancer risk [133-148]. Our mothers were an essential component of the environment of our stem cells when we were in utero, because they provided multiple signals and nutrients that regulated the behavior and fate of our first stem cells. Understanding the magnitude and the changing nature of the stem cell environment, and its importance in controlling stem cell behavior and fate, is crucial for understanding carcinogenesis.

The following analogy, which is based the seed and soil hypothesis developed by Patel to explain the organ-preference patterns of tumor metastasis [149], may be useful to easily see the amplitude and importance of the stem cell environment in carcinogenesis. Consider that the cell that gives rise to cancer is a seed and cancer is a tree. Carcinogenesis would be the process by which the seed gives rise to the tree. The changes occurring in the seed are necessary but not sufficient to generate the tree. The seed will not germinate and the tree will not grow unless they are in a soil with specific chemical and physical properties (e.g., mineral and nutrient composition, $\mathrm{pH}$, porosity, etc). But even if the seed is in a perfect soil, the tree will not grow unless the environmental conditions are favorable (e.g., light, temperature, rain, altitude, etc). The formation of a tree cannot be understood by focusing on the changes occurring inside the seed, or by focusing on the interactions between the seed and the soil. Likewise, carcinogenesis cannot be understood by focusing on the DNA alterations occurring in a cell, or by focusing on the interactions between the cell and its local microenvironment. Understanding carcinogenesis requires understanding how stem cell behavior and fate 
(i.e., quiescence, self-renewal, differentiation, migration, survival and death) are controlled and altered by the numerous and changing local, systemic and environmental factors comprising the stem cell environment (Figure 6).
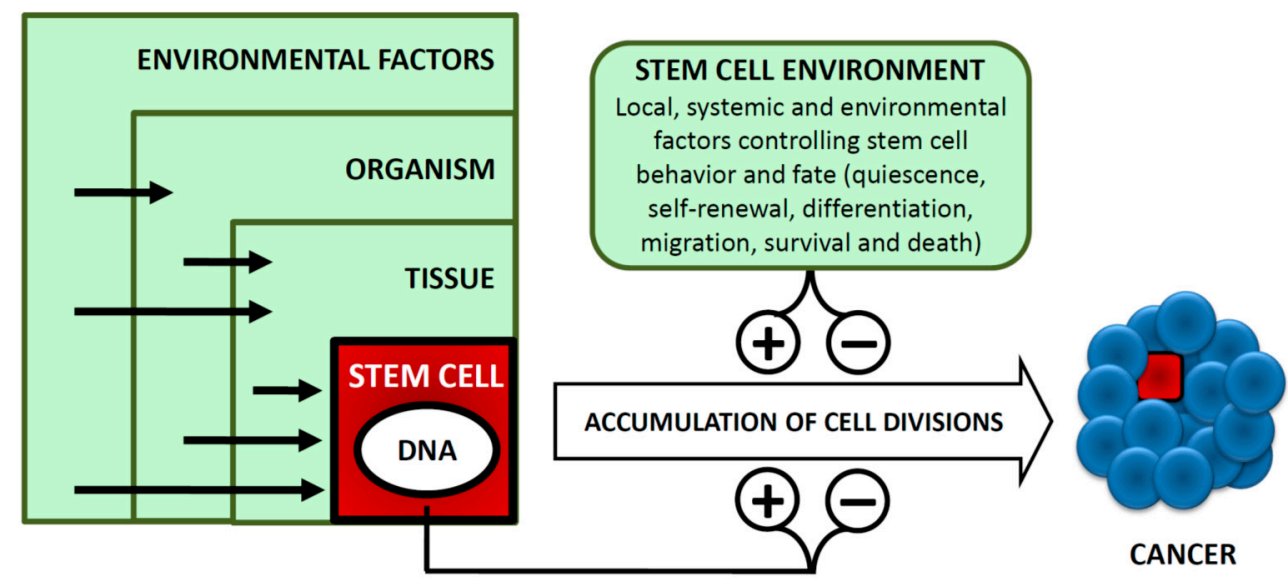

Figure 6. Cancer formation requires the cooperation between the stem cell and the stem cell environment. The accumulation of cell divisions required for carcinogenesis requires DNA changes occurring inside the stem cell (e.g., expression and repression of genes that promote and restrain cell division) and changes occurring in the stem cell environment (e.g., delivery of adequate levels of nutrients necessary for cell division, and production of the mitogenic signals that trigger the expression or repression of the genes involved in cell division). The stem cell environment comprises local factors (e.g., paracrine signals, physical interactions with other tissue components, and extracellular levels of oxygen and nutrients), systemic factors (e.g., hormones and signals from the nervous system), and environmental factors (e.g., light, microbiota, and our mothers during embryonic development). Black arrows represent that these factors can alter stem cell behavior and fate by acting on the stem cell directly or indirectly. See text for details.

Understanding cancer requires understanding that cell death is a major driver of carcinogenesis. Once our tissues are formed and we stop growing, cell death occurring during physiological tissue renewal becomes the main trigger for the accumulation of cell divisions in stem cells. Many tissues need to renew their cells frequently to maintain functionality [119,150], and most cancer cases are known to arise from these tissues. Since death cells cannot give rise to cancer, cell death occurring during tissue renewal drives carcinogenesis by acting on the local environment of the stem cells. Pathological factors (e.g., tissue injury, infections, and inflammation) and environmental factors (e.g., drinking very hot beverages) can also cause cell death and promote carcinogenesis. These cytotoxic factors will play an important role in carcinogenesis if they become chronic or persistent, because they will trigger a continuous renewal of the damaged tissue. These pathological and environmental factors do not need to cause an acute cytotoxic effect to increase the risk of cancer. They just need to cause sufficient damage to reduce the lifespan of the cells that need to be replaced by the stem cells. Stem cells will have to divide more often than usual, and they will accumulate an extra number of cell divisions that will increase their risk of malignant transformation.

It is widely acknowledged that mutagenic agents increase the risk of cancer by causing mutations in the cells that give rise to cancer. However, these agents can also promote carcinogenesis by killing or reducing the lifespan of the cells that need to be replaced by stem cells. For example, tobacco smoke can increase the risk of lung cancer not only by inducing mutations in the stem cells of the lungs, but also by inducing mutations and other damages to the differentiated cells lining the lung epithelium. These cells are actually more exposed to tobacco smoke than stem cells, which are usually sheltered in deeper layers. In addition, quiescent stem cells have powerful defense mechanisms against chemical carcinogens [151]. Damages to the cells lining the lung epithelium will shorten their life; this will force stem cells to divide more often than usual to replace the cells and ensure tissue function. Cell division will lead to cancer-related errors (Figure 5), and will also expose the DNA of the stem cell to local and systemic tobacco carcinogens [152]. 


\section{The stem cell division theory of cancer provides a new framework for understanding carcinogenesis and has important implications for cancer prevention and therapy}

We will not fully understand carcinogenesis until we learn how our body works and interacts with the environment. However, the SCDTC provides a new framework for better understanding carcinogenesis even with the currently available information. Below I discuss several examples to show that this model of carcinogenesis can explain, or provide the basis for explaining, observations that have long puzzled cancer researchers, such as the existence of cancers of unknown primary site (metastatic cancers without primary tumors) or the increased cancer risk found in people exposed to non-mutagenic factors. I also discuss that this model of carcinogenesis has important implications for cancer prevention and therapy.

It is widely accepted that metastasis is the process by which cancer cells leave primary tumors and form secondary tumors in other locations [153,154]. However, this view of metastasis does not explain the existence of cancers of unknown primary site (CUP), also called occult primary cancers. These cancers are defined as metastatic cancers for which primary tumors are not found after detailed diagnostic investigations [155-158]. These relatively common cancers are an important cause of cancer death. For example, 10,142 people in the UK died of CUP in 2014; only lung, colon, breast and prostate cancers caused more cancer deaths [12]. Because primary tumors are not found in many patients even on postmortem examination, the existence of this type of cancer is considered to be a biological mystery [155]. CUPs are also described as unrelated cancers that share the property of having a diminutive primary tumor that escapes detection. Because the site of the primary tumor usually dictates the treatment and expected outcome in patients with metastasis, this view of CUP creates uncertainty and anxiety among oncologists and patients, who may feel that their diagnostic evaluation has been incomplete [44,156-158].

According to the SCDTC, cancer originates and largely develops in stem cells. The migration ability of stem cells can therefore explain the existence of cancer of unknown primary site [44]. A cancer of unknown primary site probably arises when deregulated, premalignant or malignant stem cells migrate away from their natural tissue and give rise to a cancer in a new site before or without generating a tumor in their original location (see Figure 1 of reference [44]). It is important to realize that forming a tumor in a tissue is not necessary for stem cells to migrate away from that tissue. During embryogenesis, stem cells are known to invade tissues, migrate through the interior of the embryo, travel long distances, and establish in new places to participate in the formation of organs and tissues [159-161]. During metastasis, cells invade tissues, migrate through the lymphatic and circulatory systems, travel long distances, and establish in new tissues to form tumors [153]. Although the migration ability of stem cells is repressed after embryonic development, it probably reappears when stem cells or their environments become altered, for example, after tissue injury or under an inflammatory context [162-166]. The activation of developmental programs (e.g., epithelialmesenchymal transition programs) during metastasis can explain why, despite intensive efforts, no genetic mutation has been shown to be required for metastasis [5]; these developmental programs do not require mutations to be activated. Metastasis should be seen as the process by which cells from a tissue form tumors in other locations [44]. All metastatic cancers, including those of an unknown primary site, fit in this definition. Understanding CUP is important to reduce uncertainty and concern in oncologists and patients dealing with this type of cancer. After a detailed imaging and pathological analysis, oncologists can tell their patients with CUP that metastasis does not always involve the formation of a primary tumor, and that their diagnostic evaluation is complete $[44,47]$.

Numerous epidemiological studies have shown that drinking very hot beverages increases the risk of developing esophageal cancer [24-27]. This habit may be an important cause of cancer in some populations. For example, most inhabitants of Golestan province, Iran, drink tea at high temperatures and in quantities greater than one liter per day [24]. A case-control study conducted in this population showed that drinking hot tea and very hot tea was respectively associated with 2.07 -fold and 8.16 -fold increases in the risk of esophageal cancer compared with drinking warm tea [24]. The carcinogenicity of drinking very hot beverages [26] may explain why the incidence and mortality of this cancer in Iran are unusually high. Esophageal cancer incidence and mortality in this country is actually higher than in other countries in which smoking and heavy alcohol consumption (two major risk factors for esophageal cancer) are much more common [27,167]; for example, this cancer is the second cause of cancer-related deaths in Iran, whereas it ranks 20th in Greece and 13th in Russia [27]. The International Agency for Research on Cancer (IARC) recently classified drinking 
very hot drinks as probably carcinogenic to humans (Group 2A) [26]. However, since drinking very hot beverages is not considered to be mutagenic or mitogenic, it is unclear why this habit increases the risk of developing the disease. According to the SCDTC, when we drink something hot enough to severely damage the cells lining the esophagus, the stem cells located in deeper layers of the mucosa have to divide to produce new cells to replace the damaged cells. It has been estimated that esophageal stem cells divide every 21 days under normal conditions [74]. Regular drinking of very hot beverages probably force the stem cells of the esophagus to divide more often than usual and, therefore, to accumulate an extra number of cell divisions. The accumulation of an extra number of cell divisions in stem cells leads to the accumulation of an extra number of mutations and other cancer-promoting errors (Figure 5), which increase their risk of malignant transformation. Drinking very hot beverages increases the risk of developing esophageal cancer because this habit promotes the accumulation of cell divisions in the stem cells involved in the formation and maintenance of the esophagus [27]. Understanding and recognizing that regular consumption of very hot beverages is carcinogenic to humans is an essential step to take preventive measures. Taking preventive measures is crucial, because esophageal cancer therapy is not usually curative even when the disease is detected early (the five-year relative survival rates for esophageal cancer are $41 \%, 23 \%$ and $5 \%$ when the disease is diagnosed, respectively, at a local, regional or distant stage [11]). In addition, since consuming very hot beverages is avoidable and probably less addictive than smoking and drinking alcohol, the development of guidelines to avoiding this habit may have a major impact on prevention. In individuals and populations with this habit, simple measures like adding some cold water to a boiling cup of tea may prevent more esophageal cancer deaths than therapy, and at a lower cost. These simple and easy-to-follow guidelines could lead to significant reductions in esophageal cancer incidence and mortality in exposed populations [27].

It has been estimated that approximately $5.8 \%$ of all cancer deaths can be attributed to alcohol consumption [168]. Recent estimates indicate that the relative risk for heavy drinkers compared with nondrinkers is 5.13 for oral and pharyngeal cancer, 4.95 for esophageal cancer, 2.65 for laryngeal cancer, 2.07 for liver cancer, 1.44 for colorectal cancer and 1.61 for breast cancer [169]. However, since ethanol is not mutagenic and the carcinogenic metabolite of ethanol (acetaldehyde) is mostly produced in the liver, it is unclear why the highest risk of cancer occurs in tissues in closest contact on ingestion of ethanol [170]. Not fully understanding the mechanism of carcinogenesis of ethanol is a barrier to raise public awareness of the strong link between alcohol consumption and cancer [171]. Realizing that cell death is a key trigger for the division of stem cells can explain why alcohol consumption preferentially exerts a local carcinogenic effect [72]. Although ethanol is known to cause cell death at concentrations present in alcoholic beverages, the prevailing model of carcinogenesis is a cell-centric model in which cell death (e.g. apoptosis) is generally seen as a protective mechanism against carcinogenesis: a dead cell cannot give rise to cancer. According to the SCDTC, however, cell death plays a key role in cancer development; recall that most cancers arise from tissues in which cell death continually occurs. If we regularly drink alcoholic beverages containing cytotoxic concentrations of ethanol, we will be killing or reducing the lifespan of some of the cells lining the oral cavity, pharynx and esophagus, and we will be forcing the stem cells located in deeper layers to divide more frequently than usual. When they divide to replace the damaged cells, cancer-related errors will occur (Figure 5). It has been estimated that the stem cells in these tissues divide every 2-3 weeks under normal physiological conditions [74]. These division rates probably increase when cytotoxic concentrations of ethanol are ingested regularly. Alcohol consumption may therefore increase the risk of developing cancer of the oral cavity, pharynx and esophagus by promoting the accumulation of cell divisions in the stem cells of these tissues. Understanding the mechanism by which alcohol consumption preferentially exerts a local carcinogenic effect has an important implication for cancer prevention. The high risk of cancer of the oral cavity, pharynx and esophagus associated with alcohol consumption can be significantly reduced not only by limiting the amount of alcohol, but also by avoiding the ingestion of cytotoxic concentrations of ethanol [72]. Our unpublished data indicate that short-term exposures (2-3 seconds) to ethanol concentrations between $10 \%$ and $15 \%$ begin to cause a cytotoxic effect on human epithelial keratinocytes in a concentration-dependent manner. Choosing alcoholic beverages containing non-cytotoxic concentrations of ethanol, or diluting ethanol to non-cytotoxic concentrations, may be a simple and effective way to significantly reduce the risk of cancer of the oral cavity, pharynx and esophagus in alcohol users [72].

Epidemiological studies have shown that exposure to non-ionizing radiations can increase the risk of developing some types of cancer [34,172,173]. The human evidence of carcinogenicity is conflicting for some cancers, but it is consistent for others. For example, numerous epidemiological studies have shown a positive 
association between exposure to extremely low-frequency electromagnetic fields (ELF-EMFs) and childhood leukemia; ELF-EMFs are non-ionizing radiations typically emitted by power lines, electrical wiring and electrical appliances. It has repeatedly been observed that exposures greater than 0.3-0.4 microtesla $(\mu \mathrm{T})$ increase the risk by approximately $1.5-2$ fold. A pooled analysis published in 2000 , which included nine wellconducted studies, reported a twofold increase in risk of childhood leukemia among children with exposures of $0.4 \mu \mathrm{T}$ or higher (RR: 2.0; 95\% CI: 1.27-3.13; $P$ value: 0.002 ); adjustment for potential confounding variables did not appreciably change the results [28]. Another pooled analysis published the same year, which included 15 studies based on less restrictive inclusion criteria, showed a relative risk of 1.7 for exposure above $0.3 \mu \mathrm{T}$ [29]. New studies are in line with these large pooled analyses [30,31,174-176]. For example, a meta-analysis based on 11,699 cases and 13,194 controls showed that the relative risk was 1.57 for exposure above $0.4 \mu \mathrm{T}$ [31]. It has been estimated that $2 \%$ of childhood leukemia cases in Europe are attributable to ELF-EMFs [32,33]. The International Agency for Research on Cancer has classified ELF-EMFs as possibly carcinogenic to humans (Group 2B) [34]. However, it is considered unlikely that ELF-EMFs can cause cancer, because this type of radiation does not have enough energy to damage the DNA. Not having a biological explanation for the epidemiological link between ELF-EMFs and childhood leukemia is a barrier to develop guidelines to protect children and pregnant women from this type of radiation. Currently, guidelines for limiting exposure to ELF-EMFs are far above the levels found to increase the risk of childhood leukemia in human studies; the typical guideline limit for the general public is $100 \mu \mathrm{T}$ at $50 \mathrm{~Hz}$ and $83 \mu \mathrm{T}$ at $60 \mathrm{~Hz}$ [177]. Although children are particularly vulnerable to EMFs [178], this guideline limit is the same for adults and children.

The SCDTC provides a new framework for explaining the link between exposure to non-ionizing radiations and cancer. According to this theory, the risk of having cancer is not only increased by mutagenic agents or by agents that induce a direct mitogenic effect, but also by any factor that promotes the accumulation of cell divisions in stem cells by acting on the stem cell or on the stem cell environment. Evidence indicates that leukemia arises from hematopoietic stem cells (HSCs) [179-183]. It is also known that HSCs migrate during embryonic development and early childhood; the migration of HSCs allows different sites to participate in hematopoiesis at different moments in life [184,185]. Importantly, numerous investigations have shown that ELF-EMFs can stimulate the division of stem cells and promote tissue regeneration [34,186-192]. In addition, cell migration is regulated by physiological electric currents [123,193195], and ELF-EMFs are known to induce electric currents that can alter cell migration $[34,88,191,192,196-$ 198]. Exposure to ELF-EMFs may therefore disrupt the migration of HSCs and alter their fate. HSCs might reach an abnormal location more permissive for cell division upon disturbance by ELF-EMFs. Disruption of tissue polarity by ELF-EMFs may also alter the balance between symmetric and asymmetric cell division in stem cells $[88,199]$; this can lead to changes in stem cell fates that can promote the accumulation of cell divisions in stem cells (Figure 2). Although the precise mechanism by which ELF-EMFs increase the risk of childhood leukemia remains to be elucidated, evidence indicates that ELF-EMFs may promote the accumulation of cell divisions in HSCs through a direct or indirect mitogenic effect. Unlike the somatic mutation theory, the SCDTC is compatible with the evidence of carcinogenicity shown by ELF-EMFs in numerous human studies. This should be sufficient to admit that such evidence of carcinogenicity is not an epidemiological artifact caused by bias, confounding or change. Not yet fully understanding how ELF-EMFs increase the risk of childhood leukemia should not be a barrier to develop more restrictive guidelines to protect children and pregnant women from these radiations; the human evidence of carcinogenicity is already available. Taking protective measures can reduce the incidence of childhood leukemia in populations now exposed to this type of radiation [200].

Chemoprevention is the use of drugs to prevent or delay the development of disease. This preventive approach is widely used in the management of cardiovascular diseases. Physicians do not wait until people have cardiovascular accidents to start fighting these health problems. Because hypertension and hypercholesterolemia are known to play a crucial role in the development of cardiovascular complications, doctors prescribe drugs to control blood pressure and cholesterol levels and thus prevent future complications. This preventive strategy has significantly contributed to the reduction in cardiovascular mortality observed in developed countries during the last several decades [201]. Cancer chemoprevention, however, is restricted to a few anti-hormone drugs for some subtypes of cancer. Although chemoprevention has the potential to become an essential approach to controlling cancer [202], this discipline is clearly underdeveloped, probably because it is difficult to prevent a process without knowing where it starts and how it progresses. Knowing 
that most cancers originate and largely develop in stem cells, and that the accumulation of cell division in stem cells is the main determinant for carcinogenesis, creates new opportunities for cancer chemoprevention [46]. Identifying and controlling physiological and pathological signals that stimulate the division of stem cells may prevent these cells from accumulating an excessive number of cell divisions. For example, PGE2 is known to be a key signal for the division of normal and cancer stem cells [203,204]. Since aspirin use can reduce PGE2 levels, it is not surprising that taking a daily low-dose aspirin (75-100 mg) can reduce the risk of developing and dying from cancer [27]. An analysis of multiple clinical trials, cohort studies, and casecontrol studies showed that aspirin use reduces cancer incidence by approximately $35 \%$ in colorectal cancer, $30 \%$ in esophageal and gastric cancers, $10 \%$ in breast and prostate cancers, and 5\% in lung cancer [205]. Aspirin use also reduces cancer mortality by approximately 50\% in esophageal cancer, $40 \%$ in colorectal cancer, 35\% in gastric cancer, $15 \%$ in lung and prostate cancers, and 5\% in breast cancer [205]. Aspirin can also reduce cancer mortality in patients already diagnosed with specific tumors [206,207], which suggests that aspirin can prevent the development of established tumors in addition to reducing their incidence. Although aspirin use can increase the risk of bleeding [208], this example shows that controlling the division of stem cells through chemoprevention may be a key strategy to reduce cancer incidence and mortality [27].

According to the SCDTC, most of the cell divisions and DNA alterations required for carcinogenesis are unavoidable. Cell division is necessary to produce the huge number of cells required for living, and many DNA alterations occurring during cell division are inevitable. In addition, the striking variations in cancer incidence by age and among tissues are rather similar in populations exposed to different environmental carcinogens [167]. This seems to indicate that having cancer is a matter of bad luck, and that avoiding environmental carcinogens may not be the best strategy to reduce cancer mortality [74,209,210]. However, the fact that most cancer risk is unavoidable does not mean that most cancer cases are unpreventable. For example, being old (an 'unavoidable' risk factor) is the main risk factor for most cancers, including lung cancer. Lung cancer is around 600 times more common in people over 60 years old than in people under 30 [11]. Avoidable factors do not increase cancer risk that much; tobacco use increases lung cancer risk by approximately 20 times [42]. However, although age is the most important risk factor for lung cancer, avoiding tobacco is known to prevent a high percentage of lung cancer cases. Avoidable risk factors such as tobacco can be seen as the 'the straw that breaks the camel's back'; they are not the major contributors in most cases, but they can be decisive (https://1.usa.gov/299vyPx). The following analogy may help reinforce this key concept. Consider that stem cells are bottles, and that cancer occurs if the water in one of the bottles reaches the top. A cancer risk factor is any factor that adds water to a bottle, the risk of having cancer is the amount of water accumulated in the bottle, and cancer occurs if the water reaches the top. Even if two-thirds of the bottle were filled as a consequence of random mistakes associated with unavoidable cell divisions, cancer would not occur if we avoid the cancer-risk factor contributing the last drop of water. Preventing a small percentage of cancer risk can prevent many cancer cases. This explains why avoiding tobacco (a minor cancer risk factor compared with age) prevents many lung cancer cases. Therefore, the fact that much cancer risk is unavoidable does not mean that most cancer cases are unpreventable.

Avoiding cancer risk factors can partially protect stem cells from becoming malignant. This partial protection may be sufficient to avoid in many cases 'the drop of water that fills the bottle' and will lead to a cancer-free life in many cases. In other cases, however, primary prevention efforts will not stop stem cells from becoming malignant. Stem cells have to divide, and some errors occurring during cell division are unavoidable. But secondary prevention is still possible in these cases. The accumulation of DNA alterations in stem cells can make them vulnerable to specific pharmacological (chemoprevention) and nonpharmacological interventions. Finding a preventive strategy to selectively kill premalignant stem cells before they give rise to cancer is possible. In our analogy, these preventive strategies consist of breaking the bottle before the water reaches the top. Finding ways to selectively eliminate premalignant stem cells would make a major impact on cancer prevention [27].

The SCDTC opens new ways to treat cancer. For example, it is widely assumed that drug therapy is the only way to treat cancer patients when local therapies are no longer indicated. According to the SCDTC, advanced cancers can also be treated without drugs by manipulating the environment of cancer cells. The stem cell environment is not only crucial for carcinogenesis (Figure 6), but also for cancer evolution and survival. As discussed elsewhere [68,211], evolution and survival not only depend on the acquisition of beneficial DNA changes, but also on favorable environments for these DNA changes. Mutations that provide 
a survival benefit under a specific environment may be lethal under a different environment. According to the SCDTC, cancer cells can be selectively killed by altering the environment under which they have evolved. Importantly, food availability is a critical environmental factor, and all cancer cells have acquired DNA alterations under environments in which the levels and ratios of most food constituents (i.e., macronutrients and micronutrients) have remained relatively constant. For example, normal diets provide the 20 proteinogenic amino acids at relatively constant levels and ratios. We recently proposed that it is possible to create a lethal environment for cancer cells with a protein-free artificial diet in which the levels and ratios of specific amino acids are manipulated [212]. The aim of this anticancer strategy is to create challenging amino acid imbalances to force cells to activate genetic programs to obtain adequate levels of each of the 20 proteinogenic amino acids. Normal cells would use their functional genome to adapt to and resist this temporal challenging environment. Cancer cells, however, would be unable to do so, because their DNA alterations would compromise their ability to activate the genetic programs required to survive the new environment [212]. Our preliminary in vivo experiments suggest that this strategy has potential for the treatment of advanced cancers. One of our artificial diets is improving the efficacy of the standard treatment sunitinib in a model of renal cell carcinoma with immunocompetent mice. Under our challenging experimental protocol [213], sunitinib treatment improves mice survival but does not cure any of the animals. Several (but not all) of the mice fed with our artificial diet are alive and without any sign of disease. Although our data are still preliminary, they suggest that targeting the cancer environment may be useful not only to delay cancer progression, but also to selectively eliminate cancer cells in vivo.

\section{Concluding remarks}

According to the stem cell division theory of cancer, cell division is the key event in carcinogenesis. It is well known that cell division is necessary for cancer cell proliferation and tumor growth. This theory says that cell division is also necessary for the transformation of a normal cell into a cancer cell. The more cell divisions a stem cell has accumulated from the zygote, the higher the probability that the stem cell will divide uncontrollably to form a cancer. In other words, since cell division can lead to cancer-promoting errors that deregulate cell division (Figure 5), the accumulation of cell divisions makes cell division go out of control. This theory also says that carcinogenesis largely develops in stem cells (Figure 4). No other cell type can hold our DNA long enough to accumulate the multiple DNA changes required for carcinogenesis and, at the same time, go through the numerous cycles of cell divisions required for the malignant transformation of the cell. In addition, stem cells have the exclusive potential to produce an unlimited number of cells until the end of the life of an organism or tissue. Under normal conditions, stem cells use this potential to produce the large number of cells required for living. After malignant transformation, they use this potential to produce the cancer cells required for tumor formation and growth. Figure 7 summarizes this theory of carcinogenesis and the prevailing model of carcinogenesis (the somatic mutation theory of cancer). 


\section{SOMATIC MUTATION THEORY OF CANCER}
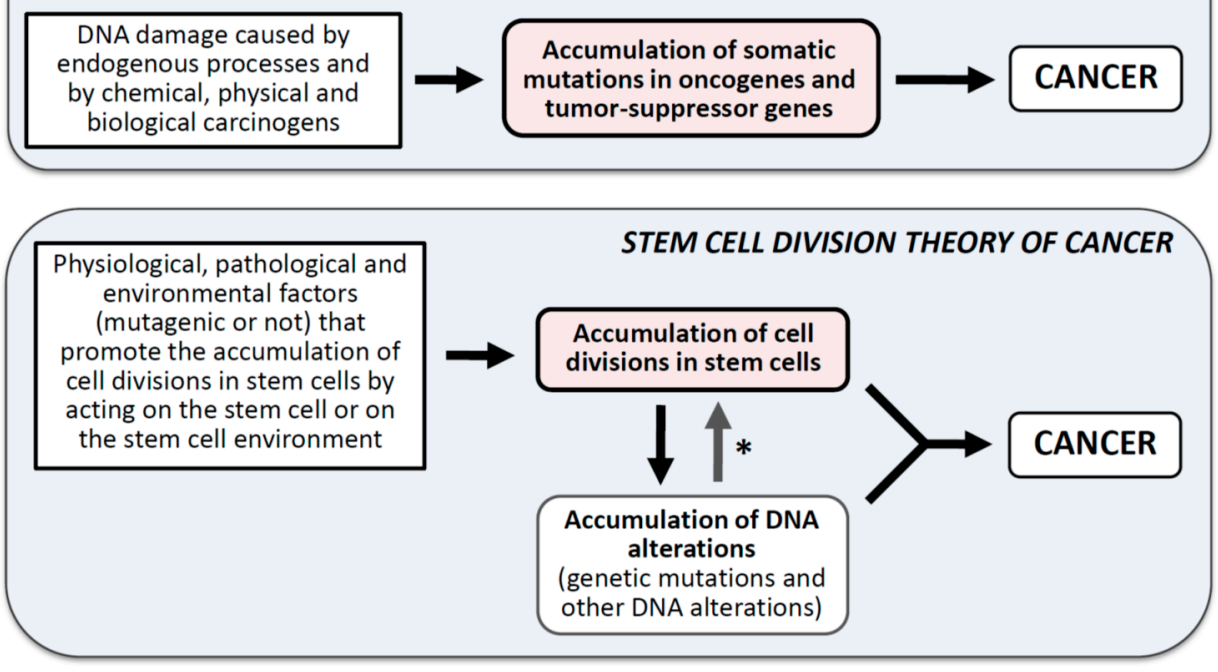

Figure 7. Prevailing model of carcinogenesis (somatic mutation theory of cancer) and proposed model of carcinogenesis (stem cell division theory of cancer). According to the somatic mutation theory, the main biological cause of cancer is the multistep accumulation of mutations in oncogenes and tumorsuppressor genes. If a cell acquires a particular set of mutations in these genes, the cell will acquire the capacity to produce the cells required for cancer formation and growth. These mutation are caused by DNA damage generated by endogenous processes (e.g., reactive oxygen species produced during metabolism) and by exposure to environmental carcinogens (e.g., tobacco chemicals, ionizing radiations, viruses and bacteria). According to the stem cell division theory, the main biological cause of cancer is the accumulation of cell divisions in stem cells. The accumulation of cell divisions in stem cells drives the accumulation of the DNA alterations required for carcinogenesis, and also the formation and growth of the abnormal cell populations required for cancer to occur. These cell divisions are caused by the sum of a variety of physiological, pathological and environmental factors. These factors not only include DNA damage caused by endogenous processes or by environmental carcinogens. They also include, for example, physiological changes in the levels of hormones and growth factors, cell death occurring during physiological tissue renewal, cell death (or cellular damage) occurring during pathological conditions (e.g., tissue injury, inflammation, and infection), and exposure to non-mutagenic environmental factors. According to the SCDTC, cancer formation requires both the accumulation of cell divisions and DNA alterations in stem cells. At the initial stages of carcinogenesis, the accumulation of DNA alterations is a consequence of the accumulation of cell divisions rather than a cause. At the final stages of carcinogenesis, however, the pathway becomes reversible $(*)$, and both events form a vicious circle that drives cancer formation and growth. According to the SCDTC, the risk of developing cancer is not only increased by mutagenic factors, but also by any factor that promotes the accumulation of cell divisions in stem cells by acting on the stem cell or on the stem cell environment. See sections 3.2 and 3.3 for details.

The SCDTC is strongly supported by results from numerous human studies involving thousands of millions of people around the world. Cancer registries show how many of us are diagnosed with cancer every year, the type of cancer we have, and the age at which the disease is diagnosed. Although people from different countries are often exposed to different carcinogens, cancer registries constantly show that some cancers are much more common than others, and that the incidence of most cancers changes considerably with age $[11,12,167]$. These differences in cancer incidence are not only constant, but also striking. The SCDTC is primarily based on analysis of these differences in cancer incidence. For example, the idea that cell division is the key event in carcinogenesis is based on the marked differences in cancer incidence among tissues with different renewal capacities. Cancer registries show that most cancers occur in tissues that renew their cells frequently, that is, in tissues whose cells accumulate many cell divisions throughout life. Cancer almost never arises from tissues whose cells rarely divide, even though these tissues are also exposed to naturally-occurring DNA damages and to environmental carcinogens. The differences in cancer incidence among tissues with different renewal capacities are striking; colon cancer is over 100,000 times more common than heart cancer (Table 1). To realize how large these differences are, recall that lung cancer incidence in heavy smokers is only 20 times higher than in never smokers [42]. The striking correlation 
recently found between the lifetime number of stem cell divisions accumulated by a tissue and the incidence of cancer in that tissue [74,76] strongly support that the accumulation of cell divisions in stem cells is the main determinant of carcinogenesis (section 3.3). Cancer registries also show that our risk of cancer increases dramatically with age (Figure 1A). For example, the probability of being diagnosed with lung cancer is approximately 600 times higher in people over 60 years old than in people under 30 [11]. The marked increase in cancer incidence with age strongly supports the idea that cancer is the end-result of the accumulation of cell divisions in stem cells. Cancer incidence increases with age because the stem cells of many of our tissues accumulate cell divisions with age. Many tissues must accumulate cell divisions in stem cells to replace damaged cells and maintain tissue function throughout life.

To be widely accepted, a cancer theory must be compatible with the striking variations in cancer incidence by age and among tissues constantly shown by all cancer registries. A cancer theory cannot be correct if it cannot explain why people around the world develop some cancers at different frequencies than others, and why the highest risk of developing each type of cancer almost always occur at a specific moment in life. Theories primarily based on data from laboratory studies may be compromised by assumptions and experimental manipulations inherent to any experimental research. Laboratory data can demonstrate that a normal differentiated cell can be transformed into a tumorigenic cancer cell by inserting a set of mutations commonly found in human tumor samples [66,214,215]. However, this does not mean that human cancers occur because differentiated cells acquire such a set of mutations. One could also demonstrate that a traffic accident can be caused by breaking the ribs of a driver, but this does not mean that traffic accidents occur because drivers suffer this type of injuries (see traffic accident analogy in section 3.1). In addition, data from laboratory studies are usually based on few experiments (typically three repetitions) with a limited number of samples under experimental conditions that we have designed to demonstrate our hypotheses. Unlike laboratory studies, cancer statistics provide observational data that are not biased by experimental designs. The age at which a person is diagnosed with cancer, and the type of cancer he or she has, leave little room for bias. In addition, these observational data are based on studies involving millions of people, which are repeated almost every year in many parts or the world. To be widely accepted, a cancer theory should explain, for example, why lung cancer in non-smokers is diagnosed thousands of times more frequently than heart cancer in smokers. It should also explain not only why cancer incidence increases dramatically with age, but also why cancer incidence decreases late in life for many cancers and peaks at different moments in life for specific cancer types (Figure 1). The somatic mutation theory cannot easily explain the first observation; mutagenic agents resulting from tobacco smoke can enter the bloodstream and reach all tissues and organs including the heart $[152,216]$. Recent evidence actually indicates that the lifetime accumulation of mutations in our tissues does not explain the variation in cancer risk across tissues [10]. The somatic mutation theory can neither explain why the accumulation of mutations occurring during a person's lifetime is not translated into an increase in cancer incidence from the beginning of life until death (Figure 1). Additional evidence challenges the somatic mutation theory of cancer [13,68,211,217,218].

Since the somatic mutation theory cannot explain important aspects of carcinogenesis, alternative models of cancer are gaining support. This is the case of the Tissue Organization Field Theory (TOFT) $[13,219,220]$. According to TOFT, cancer is a problem of tissue organization that arises from disruption of the interactions between the cell and other tissue components. Tissue organization would be disrupted by intercellular chemical signals, mechanical forces, and bioelectric changes. Because all of these changes are known to play an important role in embryonic development, this theory is often summarized as 'development gone awry' [13,219]. As discussed previously, the disruption of interactions between a cell and other tissue components plays a crucial role in carcinogenesis. In addition, tumor formation and growth inevitably leads to tissue disorganization, which in turn promotes cancer progression. However, this theory of carcinogenesis does not explain the variations in cancer incidence by age and among tissues constantly observed in human populations. It does not explain, for example, why lung tissue in non-smokers becomes disorganized thousands of times more commonly than heart tissue in smokers. It neither explains why lung, prostate and breast tissues become disorganized hundreds of times more frequently in people in their 70s than in people in their 20s, or why these tissues become disorganized less frequently in people in their $80 \mathrm{~s}$ than in people in their 70s (Figure 1). It has also been proposed that the key event in carcinogenesis is the acquisition of a selfdefined fitness function (a loss of communication between the cell and its local environment) [68], an aberrant pH regulation [221,222], or an alteration in oxygen metabolism [223]. Although these views of carcinogenesis can explain important aspects of the disease [68,221,223], they can neither explain the variations in cancer 
incidence by age and among tissues. These models of carcinogenesis do not explain why the acquisition of a self-defined fitness function, the development of an aberrant $\mathrm{pH}$ regulation, or the acquisition of an alteration in oxygen metabolism occurs thousands of times more frequently in the lungs of non-smokers than in the heart of smokers. They neither explain why the highest risk of developing these events increases with age for some cancer types, but not for others (Figure 1).

According to the SCDTC, the incidence of lung cancer in non-smokers is much higher than the incidence of heart cancer in smokers mainly because the stem cells involved in the formation and maintenance of the lungs accumulate more cell divisions than those involved in the formation and maintenance of the heart [224,225]. Unlike the heart, the lungs must accumulate cell divisions in stem cells to periodically replace damaged cells and thus maintain tissue function throughout life. The heart does not usually need to renew their cells to maintain functionality and, therefore, their stem cells do not need to accumulate cell divisions once the heart is formed. The accumulation of DNA damage in cardiac stem cells induced by tobacco carcinogens is insufficient to stimulate their division, because their local and systemic extracellular environment is not permissive for cell division under normal conditions. As explained previously, cancer incidence decreases late in life for most cancers and peaks at different moments in life for specific cancers because cell division must be active during the whole process of carcinogenesis. The accumulation of cell divisions and DNA alterations in a cell will not lead to cell division and cancer formation if the extracellular environment becomes less permissive or stops being permissive for cell division. Realizing that the stem cells of different tissues divide in response to different local and systemic extracellular signals, and that the levels of some of these signals change at different moments in life, is crucial to understand the variations in cancer incidence by age. The known decline in stem cell functionality occurring in most tissues late in life may also be caused by a reduction in the number of stem cells and by DNA changes (e.g., epigenetic changes and/or telomere shortening) occurring in the stem cells [11].

The SCDTC applies to all types of cancer, including those arising from somatic cells (cells whose DNA is not transmitted to new individuals) and those arising from germline cells (cells that give rise to egg cells and sperm cells, and whose DNA can be transmitted over generations). Like for other cancers, the accumulation of cell divisions and DNA alterations in our germline stem cells (embryonic and adult) drives the development of germline tumors. These DNA alterations can also alter the risk of any type of cancer in our progeny, like the DNA changes that took place in the germline cells of our ancestors is influencing our cancer risk. As an aside, although the DNA alterations acquired by germline cells can be transmitted over generations, the risk of cancer does not necessarily increase over generations because the accumulation of an excessive number of DNA aberrations would lead to infertility in progenitors, miscarriage, premature death of the descendants (before the reproductive period) or infertility in the descendants. Our risk of cancer is influenced by DNA changes that have occurred during human evolution, including those that happened in our parents and those that occurred millions of years ago. However, it is convenient to consider that our risk of cancer starts when our biological life begins, that is, in the zygote.

Cancer research over the last several decades has been driven by a cell-centric theory in which carcinogenesis is caused and driven by the accumulation of mutations in oncogenes and tumor suppressor genes. Cancer incidence and mortality have not changed much during the hegemony of this model of carcinogenesis [226,227]. This limited progress cannot only be attributed to an ageing population, because the mortality rates of other age-related diseases, such as heart disease, have decreased notably during the same period [201,228]. Placing the focus inside the genome is an obstacle to understanding important aspects of the disease. It is like trying to understand the process by which a seed gives rise to a tree by focusing on the DNA changes occurring in the seed and ignoring the influence of the soil and the environment on this process. Not understanding the disease is a barrier to develop more effective ways to reduce cancer incidence and mortality. The somatic mutation theory may also be an obstacle to protect populations from non-mutagenic cancer risk factors. For example, if most textbooks say that cancer is caused by mutations and drinking very hot beverages does not cause mutations, how do we explain to people that this dietary habit probably increases their risk of developing esophageal cancer [24-27]? If non-ionizing radiations (e.g., ELF-EMFs) do not have enough energy to cause mutations, how do we convince health agencies to develop more restrictive guidelines to protect exposed populations from this type of radiation [28-34]? If working at night does not cause mutations, is it necessary to alarm women working at night by telling them that circadian disruption by electrical lighting probably increases their risk of developing breast cancer [20-23]? The SCDTC provides a new framework to integrate the huge amount of apparently unrelated information gathered during the last 
several decades into a logical principle. Having a consistent model of carcinogenesis, compatible with cancer incidence data, is important to turn cancer research efforts into a powerful tool for reducing cancer incidence and mortality. Although the accumulation of mutations in oncogenes and tumor-suppressor genes is crucial for the development of many cancers, changing the focus from accumulation of somatic mutations in driver genes to accumulation of cell divisions in stem cells is necessary to understand carcinogenesis and to reduce the burden of the disease.

\section{Conflicts of Interest}

The author declares no conflict of interest.

\section{Acknowledgements}

I thank my group for critical reading of the manuscript and helpful discussions.

\section{References}

1. Lopez-Lazaro M. What Is The Main Cause Of Cancer? Cancer Stud. Ther. J. 2016; 1(1): 1-2.

2. Nordling CO. A new theory on cancer-inducing mechanism. Br. J Cancer. 1953; 7(1): 68-72.

3. Armitage P, Doll R. The age distribution of cancer and a multi-stage theory of carcinogenesis. Br. J Cancer. 1954; 8(1): $1-12$.

4. Tomasetti C, Marchionni L, Nowak MA, Parmigiani G, Vogelstein B. Only three driver gene mutations are required for the development of lung and colorectal cancers. Proc. Natl. Acad. Sci. U. S. A. 2015; 112(1): 118-123.

5. Vogelstein B, Kinzler KW. The Path to Cancer --Three Strikes and You're Out. N. Engl. J. Med. 2015; 373(20): 1895-1898.

6. Vogelstein B, Kinzler KW. Cancer genes and the pathways they control. Nat. Med. 2004; 10(8): 789-799.

7. Stratton MR, Campbell PJ, Futreal PA. The cancer genome. Nature. 2009; 458(7239): 719-724.

8. Vogelstein B, Papadopoulos N, Velculescu VE, Zhou S, Diaz LA, Jr., Kinzler KW. Cancer genome landscapes. Science. 2013; 339(6127): 1546-1558.

9. Martincorena I, Campbell PJ. Somatic mutation in cancer and normal cells. Science. 2015; 349(6255): 1483-1489.

10. Blokzijl F, de Ligt J, Jager M, Sasselli V, Roerink S, Sasaki N, Huch M, Boymans S, Kuijk E, Prins P, Nijman IJ, Martincorena I, Mokry M et al. Tissue-specific mutation accumulation in human adult stem cells during life. Nature. 2016; 538(7624): 260-264.

11. Howlader N, Noone AM, Krapcho M, Miller D, Bishop K, Kosary CL, Yu M, Ruhl J, Tatalovich Z, Mariotto A, Lewis DR, Chen HS, Feuer EJ, Cronin KA (eds). SEER Cancer Statistics Review, 1975-2014, National Cancer Institute. Bethesda, MD, https://seer.cancer.gov/csr/1975_2014/

12. Cancer Research UK, http://www.cancerresearchuk.org/health-professional/cancer-statistics/

13. Baker SG. A cancer theory kerfuffle can lead to new lines of research. J. Natl. Cancer Inst. 2014; 107(2): dju405.

14. Greenman C, Stephens P, Smith R, Dalgliesh GL, Hunter C, Bignell G, Davies H, Teague J, Butler A, Stevens C, Edkins S, O'Meara S, Vastrik I et al. Patterns of somatic mutation in human cancer genomes. Nature. 2007; 446(7132): 153-158.

15. Mack SC, Witt H, Piro RM, Gu L, Zuyderduyn S, Stutz AM, Wang X, Gallo M, Garzia L, Zayne K, Zhang X, Ramaswamy V, Jager $\mathrm{N}$ et al. Epigenomic alterations define lethal CIMP-positive ependymomas of infancy. Nature. 2014; 506(7489): 445-450.

16. Versteeg R. Cancer: Tumours outside the mutation box. Nature. 2014; 506(7489): 438-439.

17. Beral V. Breast cancer and hormone-replacement therapy in the Million Women Study. Lancet. 2003; 362(9382): 419-427.

18. Grady D, Gebretsadik T, Kerlikowske K, Ernster V, Petitti D. Hormone replacement therapy and endometrial cancer risk: a meta-analysis. Obstet. Gynecol. 1995; 85(2): 304-313.

19. Morch LS, Lokkegaard E, Andreasen AH, Kruger-Kjaer S, Lidegaard O. Hormone therapy and ovarian cancer. JAMA. 2009; 302(3): 298-305.

20. Schernhammer ES, Laden F, Speizer FE, Willett WC, Hunter DJ, Kawachi I, Colditz GA. Rotating night shifts and risk of breast cancer in women participating in the nurses' health study. J. Natl. Cancer Inst. 2001; 93(20): $1563-$ 1568.

21. Hansen J. Increased breast cancer risk among women who work predominantly at night. Epidemiology. 2001; 12(1): 74-77. 
22. Stevens RG, Brainard GC, Blask DE, Lockley SW, Motta ME. Breast cancer and circadian disruption from electric lighting in the modern world. CA Cancer J. Clin. 2014; 64(3): 207-218.

23. Straif K, Baan R, Grosse Y, Secretan B, Ghissassi FE, Bouvard V, Altieri A, Benbrahim-Tallaa L, Cogliano V. Carcinogenicity of shift-work, painting, and fire-fighting. Lancet Oncol. 2007; 8(12): 1065-1066.

24. Islami F, Pourshams A, Nasrollahzadeh D, Kamangar F, Fahimi S, Shakeri R, Abedi-Ardekani B, Merat S, Vahedi $\mathrm{H}$, Semnani S, Abnet CC, Brennan P, Moller H et al. Tea drinking habits and oesophageal cancer in a high risk area in northern Iran: population based case-control study. BMJ. 2009; 338:b929.

25. Islami F, Boffetta P, Ren JS, Pedoeim L, Khatib D, Kamangar F. High-temperature beverages and foods and esophageal cancer risk--a systematic review. Int. J. Cancer. 2009; 125(3): 491-524.

26. Loomis D, Guyton KZ, Grosse Y, Lauby-Secretan B, El Ghissassi F, Bouvard V, Benbrahim-Tallaa L, Guha N, Mattock H, Straif K. Carcinogenicity of drinking coffee, mate, and very hot beverages. Lancet Oncol. 2016; 17(7): 877-878.

27. Lopez-Lazaro M. Understanding why aspirin prevents cancer and why consuming very hot beverages and foods increases esophageal cancer risk. Controlling the division rates of stem cells is an important strategy to prevent cancer. Oncoscience. 2015; 2(10): 849-856.

28. Ahlbom A, Day N, Feychting M, Roman E, Skinner J, Dockerty J, Linet M, McBride M, Michaelis J, Olsen JH, Tynes T, Verkasalo PK. A pooled analysis of magnetic fields and childhood leukaemia. Br. J. Cancer. 2000; 83(5): 692-698.

29. Greenland S, Sheppard AR, Kaune WT, Poole C, Kelsh MA. A pooled analysis of magnetic fields, wire codes, and childhood leukemia. Childhood Leukemia-EMF Study Group. Epidemiology. 2000; 11(6): 624-634.

30. Kheifets L, Ahlbom A, Crespi CM, Draper G, Hagihara J, Lowenthal RM, Mezei G, Oksuzyan S, Schuz J, Swanson J, Tittarelli A, Vinceti M, Wunsch F, V. Pooled analysis of recent studies on magnetic fields and childhood leukaemia. Br. J. Cancer. 2010; 103(7): 1128-1135.

31. Zhao L, Liu X, Wang C, Yan K, Lin X, Li S, Bao H, Liu X. Magnetic fields exposure and childhood leukemia risk: a meta-analysis based on 11,699 cases and 13,194 controls. Leuk. Res. 2014; 38(3): 269-274.

32. Grellier J, Ravazzani P, Cardis E. Potential health impacts of residential exposures to extremely low frequency magnetic fields in Europe. Environ. Int. 2014; 62:55-63.

33. Schuz J, Dasenbrock C, Ravazzani P, Roosli M, Schar P, Bounds PL, Erdmann F, Borkhardt A, Cobaleda C, Fedrowitz M, Hamnerius Y, Sanchez-Garcia I, Seger R et al. Extremely low-frequency magnetic fields and risk of childhood leukemia: A risk assessment by the ARIMMORA consortium. Bioelectromagnetics. 2016; 10. DOI: 10.1002/bem.21963

34. International Agency for Research on Cancer. IARC Monographs on the Evaluation of Carcinogenic Risks to Humans. Volume 80: Non-Ionizing Radiation, Part 1: Static and Extremely Low-Frequency (ELF) Electric and Magnetic Fields. 2002. Available online: http://monographs.iarc.fr/ENG/Monographs/vol80/index.php

35. Magnon C, Hall SJ, Lin J, Xue X, Gerber L, Freedland SJ, Frenette PS. Autonomic nerve development contributes to prostate cancer progression. Science. 2013; 341(6142): 1236361.

36. Zhao CM, Hayakawa Y, Kodama Y, Muthupalani S, Westphalen CB, Andersen GT, Flatberg A, Johannessen H, Friedman RA, Renz BW, Sandvik AK, Beisvag V, Tomita H et al. Denervation suppresses gastric tumorigenesis. Sci. Transl. Med. 2014;6(250): 250ra115.

37. Diederichs S, Bartsch L, Berkmann JC, Frose K, Heitmann J, Hoppe C, Iggena D, Jazmati D, Karschnia P, Linsenmeier M, Maulhardt T, Mohrmann L, Morstein J et al. The dark matter of the cancer genome: aberrations in regulatory elements, untranslated regions, splice sites, non-coding RNA and synonymous mutations. EMBO Mol. Med. 2016; e201506055.

38. Dawson MA, Kouzarides T. Cancer epigenetics: from mechanism to therapy. Cell. 2012; 150(1): 12-27.

39. Suva ML, Riggi N, Bernstein BE. Epigenetic reprogramming in cancer. Science. 2013; 339(6127): 1567-1570.

40. Gordon DJ, Resio B, Pellman D. Causes and consequences of aneuploidy in cancer. Nat. Rev. Genet. 2012; 13(3): 189-203.

41. Khurana E, Fu Y, Chakravarty D, Demichelis F, Rubin MA, Gerstein M. Role of non-coding sequence variants in cancer. Nat Rev. Genet. 2016; 17(2): 93-108.

42. Doll R, Peto R, Wheatley K, Gray R, Sutherland I. Mortality in relation to smoking: 40 years' observations on male British doctors. BMJ. 1994; 309(6959): 901-911.

43. Oliveira GH, Al Kindi SG, Hoimes C, Park SJ. Characteristics and Survival of Malignant Cardiac Tumors: A 40Year Analysis of $>500$ Patients. Circulation. 2015; 132(25): 2395-2402.

44. Lopez-Lazaro M. The migration ability of stem cells can explain the existence of cancer of unknown primary site. Rethinking metastasis. Oncoscience. 2015; 2(5): 467-475.

45. Lopez-Lazaro M. Stem cell division theory of cancer. Cell Cycle 2015; 14(16): 2547-2548.

46. Lopez-Lazaro M. Cancer arises from stem cells: opportunities for anticancer drug discovery. Drug Discov. Today. 2015; 20(11): 1285-1287.

47. Lopez-Lazaro M. Understanding cancer: 15 questions and answers. ResearchGate, 2016; DOI: 10.13140/RG.2.1.4180.6323; http://dx.doi.org/10.13140/RG.2.1.4180.6323. 
48. Clevers H. What is an adult stem cell? Science. 2015; 350(6266): 1319-1320.

49. Tetteh PW, Farin HF, Clevers H. Plasticity within stem cell hierarchies in mammalian epithelia. Trends Cell Biol. 2015; 25(2): 100-108.

50. Visvader JE, Clevers H. Tissue-specific designs of stem cell hierarchies. Nat. Cell Biol. 2016; 18(4): 349-355.

51. Merrell AJ, Stanger BZ. Adult cell plasticity in vivo: de-differentiation and transdifferentiation are back in style. Nat. Rev. Mol. Cell Biol. 2016; 17(7): 413-425.

52. Tajbakhsh S. Stem cell: what's in a name? Nat Rep Stem Cells 2009; doi:10.1038/stemcells.2009.90.

53. Bianconi E, Piovesan A, Facchin F, Beraudi A, Casadei R, Frabetti F, Vitale L, Pelleri MC, Tassani S, Piva F, Perez-Amodio S, Strippoli P, Canaider S. An estimation of the number of cells in the human body. Ann. Hum. Biol. 2013; 40(6): 463-471.

54. Wilmut I, Schnieke AE, McWhir J, Kind AJ, Campbell KH. Viable offspring derived from fetal and adult mammalian cells. Nature. 1997; 385(6619): 810-813.

55. Takahashi K, Tanabe K, Ohnuki M, Narita M, Ichisaka T, Tomoda K, Yamanaka S. Induction of pluripotent stem cells from adult human fibroblasts by defined factors. Cell. 2007; 131(5): 861-872.

56. Blanpain C, Fuchs E. Stem cell plasticity. Plasticity of epithelial stem cells in tissue regeneration. Science. 2014; 344(6189): 1242281.

57. de Sousa e Melo, Kurtova AV, Harnoss JM, Kljavin N, Hoeck JD, Hung J, Anderson JE, Storm EE, Modrusan Z, Koeppen H, Dijkgraaf GJ, Piskol R, de Sauvage FJ. A distinct role for Lgr5+ stem cells in primary and metastatic colon cancer. Nature. 2017; 543(7647): 676-680.

58. O'Brien CA, Pollett A, Gallinger S, Dick JE. A human colon cancer cell capable of initiating tumour growth in immunodeficient mice. Nature. 2007; 445(7123): 106-110.

59. Stanger BZ. Cellular homeostasis and repair in the mammalian liver. Annu. Rev. Physiol. 2015; 77:179-200.

60. Visvader JE. Cells of origin in cancer. Nature. 2011;469(7330): 314-322.

61. Blanpain C. Tracing the cellular origin of cancer. Nat. Cell Biol. 2013; 15(2): 126-134.

62. Chaffer CL, Weinberg RA. How does multistep tumorigenesis really proceed? Cancer Discov. 2015; 5(1): 22-24.

63. Koren S, Reavie L, Couto JP, De Silva D, Stadler MB, Roloff T, Britschgi A, Eichlisberger T, Kohler H, Aina O, Cardiff RD, Bentires-Alj M. PIK3CA(H1047R) induces multipotency and multi-lineage mammary tumours. Nature. 2015; 525(7567): 114-118.

64. Van Keymeulen A, Lee MY, Ousset M, Brohee S, Rorive S, Giraddi RR, Wuidart A, Bouvencourt G, Dubois C, Salmon I, Sotiriou C, Phillips WA, Blanpain C. Reactivation of multipotency by oncogenic PIK3CA induces breast tumour heterogeneity. Nature. 2015; 525(7567): 119-123.

65. Lawson DA, Zong Y, Memarzadeh S, Xin L, Huang J, Witte ON. Basal epithelial stem cells are efficient targets for prostate cancer initiation. Proc. Natl. Acad. Sci. U. S. A. 2010; 107(6): 2610-2615.

66. Park JW, Lee JK, Phillips JW, Huang P, Cheng D, Huang J, Witte ON. Prostate epithelial cell of origin determines cancer differentiation state in an organoid transformation assay. Proc. Natl. Acad. Sci. U. S. A. 2016; 19;113(16): 4482-4487.

67. Stratton MR. Exploring the genomes of cancer cells: progress and promise. Science. 2011; 331(6024): 1553-1558.

68. Gatenby RA, Brown J. Mutations, evolution and the central role of a self-defined fitness function in the initiation and progression of cancer. Biochim. Biophys. Acta. 2017; 1867(2): 162-166.

69. Lopez-Lazaro M. Pancreatic cancer formation is gradual. ResearchGate, 2017, DOI: 10.13140/RG.2.2.16865.92009; https://doi.org/10.13140/RG.2.2.16865.92009

70. Lynch M. Rate, molecular spectrum, and consequences of human mutation. Proc. Natl. Acad. Sci. U. S. A. 2010; 19;107(3): 961-968.

71. Tomasetti C, Vogelstein B, Parmigiani G. Half or more of the somatic mutations in cancers of self-renewing tissues originate prior to tumor initiation. Proc. Natl. Acad. Sci. U. S. A. 2013; 110(6): 1999-2004.

72. Lopez-Lazaro M. A local mechanism by which alcohol consumption causes cancer. Oral Oncol. 2016; 62: 149-152.

73. Shimokawa M, Ohta Y, Nishikori S, Matano M, Takano A, Fujii M, Date S, Sugimoto S, Kanai T, Sato T. Visualization and targeting of LGR5+ human colon cancer stem cells. Nature. 2017; 545(7653): 187-192.

74. Tomasetti C, Vogelstein B. Cancer etiology. Variation in cancer risk among tissues can be explained by the number of stem cell divisions. Science. 2015; 347(6217): 78-81.

75. Wu S, Powers S, Zhu W, Hannun YA. Substantial contribution of extrinsic risk factors to cancer development. Nature. 2016; 529(7584): 43-47.

76. Tomasetti C, Li L, Vogelstein B. Stem cell divisions, somatic mutations, cancer etiology, and cancer prevention. Science. 2017; 355(6331): 1330-1334.

77. Natarajan AT. Chromosome aberrations: past, present and future. Mutat. Res. 2002; 504(1-2): 3-16.

78. Crasta K, Ganem NJ, Dagher R, Lantermann AB, Ivanova EV, Pan Y, Nezi L, Protopopov A, Chowdhury D, Pellman D. DNA breaks and chromosome pulverization from errors in mitosis. Nature. 2012; 482(7383): 53-58. 
79. Stephens PJ, Greenman CD, Fu B, Yang F, Bignell GR, Mudie LJ, Pleasance ED, Lau KW, Beare D, Stebbings LA, McLaren S, Lin ML, McBride DJ et al. Massive genomic rearrangement acquired in a single catastrophic event during cancer development. Cell. 2011; 144(1): 27-40.

80. Maher CA, Wilson RK. Chromothripsis and human disease: piecing together the shattering process. Cell. 2012; 148(1-2): 29-32.

81. Notta F, Chan-Seng-Yue M, Lemire M, Li Y, Wilson GW, Connor AA, Denroche RE, Liang SB, Brown AM, Kim JC, Wang T, Simpson JT, Beck T et al. A renewed model of pancreatic cancer evolution based on genomic rearrangement patterns. Nature. 2016; 538(7625): 378-382.

82. Wagers AJ, Christensen JL, Weissman IL. Cell fate determination from stem cells. Gene Ther. 2002; 9(10): 606612.

83. Roubinet C, Cabernard C. Control of asymmetric cell division. Curr. Opin. Cell Biol. 2014; 31:84-91.

84. Katajisto P, Dohla J, Chaffer CL, Pentinmikko N, Marjanovic N, Iqbal S, Zoncu R, Chen W, Weinberg RA, Sabatini DM. Stem cells. Asymmetric apportioning of aged mitochondria between daughter cells is required for stemness. Science. 2015; 348(6232): 340-343.

85. Smith P, Azzam M, Hinck L. Extracellular Regulation of the Mitotic Spindle and Fate Determinants Driving Asymmetric Cell Division. Results Probl. Cell Differ. 2017; 61:351-373.

86. Mukherjee S, Brat DJ. Molecular Programs Underlying Asymmetric Stem Cell Division and Their Disruption in Malignancy. Results Probl. Cell Differ. 2017; 61:401-421.

87. Morrison SJ, Kimble J. Asymmetric and symmetric stem-cell divisions in development and cancer. Nature. 2006; 441(7097): 1068-1074.

88. Campanale JP, Sun TY, Montell DJ. Development and dynamics of cell polarity at a glance. J Cell Sci. 2017; 130(7): 1201-1207.

89. Costa P, Almeida FV, Connelly JT. Biophysical signals controlling cell fate decisions: how do stem cells really feel? Int. J. Biochem. Cell Biol. 2012; 44(12): 2233-2237.

90. Trappmann B, Gautrot JE, Connelly JT, Strange DG, Li Y, Oyen ML, Cohen Stuart MA, Boehm H, Li B, Vogel V, Spatz JP, Watt FM, Huck WT. Extracellular-matrix tethering regulates stem-cell fate. Nat. Mater. 2012; 11(7): 642649.

91. Sun Y, Chen CS, Fu J. Forcing stem cells to behave: a biophysical perspective of the cellular microenvironment. Annu. Rev. Biophys. 2012; 41:519-42.

92. Wen JH, Vincent LG, Fuhrmann A, Choi YS, Hribar KC, Taylor-Weiner H, Chen S, Engler AJ. Interplay of matrix stiffness and protein tethering in stem cell differentiation. Nat. Mater. 2014; 13(10): 979-987.

93. Engler AJ, Sen S, Sweeney HL, Discher DE. Matrix elasticity directs stem cell lineage specification. Cell. 2006; 126(4): 677-689.

94. Watt FM, Huck WT. Role of the extracellular matrix in regulating stem cell fate. Nat. Rev. Mol. Cell Biol. 2013; 14(8): 467-473.

95. Burger MM. Proteolytic enzymes initiating cell division and escape from contact inhibition of growth. Nature. 1970; 227(5254): 170-171.

96. Ceccarini C, Eagle H. pH as a determinant of cellular growth and contact inhibition. Proc. Natl. Acad. Sci. U. S. A. 1971; 68(1): 229-233.

97. Martz E, Steinberg MS. The role of cell-cell contact in "contact" inhibition of cell division: a review and new evidence. J Cell Physiol. 1972; 79(2): 189-210.

98. Abercrombie M. Contact inhibition and malignancy. Nature. 1979; 281(5729): 259-262.

99. Ribatti D. A revisited concept: Contact inhibition of growth. From cell biology to malignancy. Exp. Cell Res. 2017; 20. pii: S0014-4827(17): 10.

100. Sonnenschein C, Soto AM. Carcinogenesis explained within the context of a theory of organisms. Prog. Biophys. Mol. Biol. 2016; 122(1): 70-76.

101. Lindahl T. Instability and decay of the primary structure of DNA. Nature. 1993; 362(6422): 709-715.

102. De Bont R, van Larebeke N. Endogenous DNA damage in humans: a review of quantitative data. Mutagenesis. 2004; 19(3): 169-185.

103. Swenberg JA, Lu K, Moeller BC, Gao L, Upton PB, Nakamura J, Starr TB. Endogenous versus exogenous DNA adducts: their role in carcinogenesis, epidemiology, and risk assessment. Toxicol. Sci. 2011; 120 Suppl 1:S130-45.

104. Cheng KC, Cahill DS, Kasai H, Nishimura S, Loeb LA. 8-Hydroxyguanine, an abundant form of oxidative DNA damage, causes G----T and A----C substitutions. J Biol. Chem. 1992; 267(1): 166-172.

105. Bruner SD, Norman DP, Verdine GL. Structural basis for recognition and repair of the endogenous mutagen 8oxoguanine in DNA. Nature. 2000; 403(6772): 859-866.

106. Arana ME, Kunkel TA. Mutator phenotypes due to DNA replication infidelity. Semin. Cancer Biol. 2010; 20(5): 304-311.

107. Ljungman M, Hanawalt PC. Efficient protection against oxidative DNA damage in chromatin. Mol. Carcinog. 1992; 5(4): 264-269. 
108. Eisenberg E, Levanon EY. Human housekeeping genes, revisited. Trends Genet. 2013; 29(10): 569-574.

109. Davies H, Bignell GR, Cox C, Stephens P, Edkins S, Clegg S, Teague J, Woffendin H, Garnett MJ, Bottomley W, Davis N, Dicks E, Ewing R et al. Mutations of the BRAF gene in human cancer. Nature. 2002; 417(6892): 949-954.

110. Ziv O, Geacintov N, Nakajima S, Yasui A, Livneh Z. DNA polymerase zeta cooperates with polymerases kappa and iota in translesion DNA synthesis across pyrimidine photodimers in cells from XPV patients. Proc. Natl. Acad. Sci. U. S. A. 2009; 106(28): 11552-11557.

111. Waters LS, Minesinger BK, Wiltrout ME, D'Souza S, Woodruff RV, Walker GC. Eukaryotic translesion polymerases and their roles and regulation in DNA damage tolerance. Microbiol. Mol. Biol. Rev. 2009; 73(1): 134154.

112. Lopez-Lazaro M. Does hypoxia really control tumor growth? Cell Oncol. 2006; 28(5-6): 327-329.

113. Lopez-Lazaro M. The Warburg effect: why and how do cancer cells activate glycolysis in the presence of oxygen? Anticancer Agents Med. Chem. 2008; 8(3): 305-312.

114. Allegra JC, Lippman ME. Growth of a human breast cancer cell line in serum-free hormone-supplemented medium. Cancer Res. 1978; 38(11 Pt 1): 3823-3829.

115. Dessels C, Potgieter M, Pepper MS. Making the Switch: Alternatives to Fetal Bovine Serum for Adipose-Derived Stromal Cell Expansion. Front Cell Dev. Biol. 2016; 4:115.

116. Grinspon RP, Rey RA. Anti-mullerian hormone and sertoli cell function in paediatric male hypogonadism. Horm. Res. Paediatr. 2010; 73(2): 81-92.

117. Scadden DT. The stem-cell niche as an entity of action. Nature. 2006; 441(7097): 1075-1079.

118. Morrison SJ, Scadden DT. The bone marrow niche for haematopoietic stem cells. Nature. 2014; 505(7483): $327-$ 334.

119. Clevers H, Loh KM, Nusse R. Stem cell signaling. An integral program for tissue renewal and regeneration: Wnt signaling and stem cell control. Science. 2014; 346(6205): 1248012.

120. Mohyeldin A, Garzon-Muvdi T, Quinones-Hinojosa A. Oxygen in stem cell biology: a critical component of the stem cell niche. Cell Stem Cell. 2010; 7(2): 150-161.

121. Gattazzo F, Urciuolo A, Bonaldo P. Extracellular matrix: a dynamic microenvironment for stem cell niche. Biochim. Biophys. Acta. 2014; 1840(8): 2506-2519.

122. Blackiston DJ, McLaughlin KA, Levin M. Bioelectric controls of cell proliferation: ion channels, membrane voltage and the cell cycle. Cell Cycle. 2009; 8(21): 3527-3536.

123. Levin M. Molecular bioelectricity: how endogenous voltage potentials control cell behavior and instruct pattern regulation in vivo. Mol. Biol. Cell. 2014; 25(24): 3835-3850.

124. Burns CP, Rozengurt E. Extracellular $\mathrm{Na}+$ and initiation of DNA synthesis: role of intracellular $\mathrm{pH}$ and $\mathrm{K}+\mathrm{J}$ Cell Biol. 1984; 98(3): 1082-1089.

125. Cescon M, Gattazzo F, Chen P, Bonaldo P. Collagen VI at a glance. J Cell Sci. 2015; 128(19): 3525-3531.

126. Frantz C, Stewart KM, Weaver VM. The extracellular matrix at a glance. J Cell Sci. 2010; 123(Pt 24): 4195-4200.

127. Gomella LG. Effective testosterone suppression for prostate cancer: is there a best castration therapy? Rev. Urol. 2009; 11(2): 52-60.

128. Mendez-Ferrer S, Lucas D, Battista M, Frenette PS. Haematopoietic stem cell release is regulated by circadian oscillations. Nature. 2008; 452(7186): 442-447.

129. Matsuo T, Yamaguchi S, Mitsui S, Emi A, Shimoda F, Okamura H. Control mechanism of the circadian clock for timing of cell division in vivo. Science. 2003; 302(5643): 255-259.

130. Brown SA. Circadian clock-mediated control of stem cell division and differentiation: beyond night and day. Development. 2014; 141(16): 3105-3111.

131. Puram RV, Kowalczyk MS, de Boer CG, Schneider RK, Miller PG, McConkey M, Tothova Z, Tejero H, Heckl D, Jaras M, Chen MC, Li H, Tamayo A et al. Core Circadian Clock Genes Regulate Leukemia Stem Cells in AML. Cell. 2016; 165(2): 303-316.

132. Fu L, Lee CC. The circadian clock: pacemaker and tumour suppressor. Nat Rev. Cancer. 2003; 3(5): 350-361.

133. Buchon N, Broderick NA, Chakrabarti S, Lemaitre B. Invasive and indigenous microbiota impact intestinal stem cell activity through multiple pathways in Drosophila. Genes Dev. 2009; 23(19): 2333-2344.

134. Kaiko GE, Ryu SH, Koues OI, Collins PL, Solnica-Krezel L, Pearce EJ, Pearce EL, Oltz EM, Stappenbeck TS. The Colonic Crypt Protects Stem Cells from Microbiota-Derived Metabolites. Cell. 2016; 167(4): 1137.

135. Hill MJ, Drasar BS, Hawksworth G, Aries V, Crowther JS, Williams RE. Bacteria and aetiology of cancer of large bowel. Lancet. 1971; 1(7690): 95-100.

136. Bindels LB, Porporato P, Dewulf EM, Verrax J, Neyrinck AM, Martin JC, Scott KP, Buc CP, Feron O, Muccioli GG, Sonveaux P, Cani PD, Delzenne NM. Gut microbiota-derived propionate reduces cancer cell proliferation in the liver. Br. J Cancer. 2012; 107(8): 1337-1344.

137. Zitvogel L, Galluzzi L, Viaud S, Vetizou M, Daillere R, Merad M, Kroemer G. Cancer and the gut microbiota: an unexpected link. Sci. Transl. Med. 2015; 7(271): 271 ps1. 
138. Farrell JJ, Zhang L, Zhou H, Chia D, Elashoff D, Akin D, Paster BJ, Joshipura K, Wong DT. Variations of oral microbiota are associated with pancreatic diseases including pancreatic cancer. Gut. 2012; 61(4): 582-588.

139. Schmidt BL, Kuczynski J, Bhattacharya A, Huey B, Corby PM, Queiroz EL, Nightingale K, Kerr AR, DeLacure MD, Veeramachaneni R, Olshen AB, Albertson DG. Changes in abundance of oral microbiota associated with oral cancer. PLoS. One. 2014; 9(6): e98741.

140. Garrett WS. Cancer and the microbiota. Science. 2015; 348(6230): 80-86.

141. Yan J, Herzog JW, Tsang K, Brennan CA, Bower MA, Garrett WS, Sartor BR, Aliprantis AO, Charles JF. Gut microbiota induce IGF-1 and promote bone formation and growth. Proc. Natl. Acad. Sci. U. S. A. 2016; 113(47): E7554-E7563.

142. Brennan CA, Garrett WS. Gut Microbiota, Inflammation, and Colorectal Cancer. Annu. Rev. Microbiol. 2016; 70:395-411.

143. Rooks MG, Garrett WS. Gut microbiota, metabolites and host immunity. Nat Rev. Immunol. 2016; 16(6): 341-352.

144. Donia MS, Fischbach MA. HUMAN MICROBIOTA. Small molecules from the human microbiota. Science. 2015; 349(6246): 1254766.

145. Mehta RS, Nishihara R, Cao Y, Song M, Mima K, Qian ZR, Nowak JA, Kosumi K, Hamada T, Masugi Y, Bullman S, Drew DA, Kostic AD et al. Association of Dietary Patterns With Risk of Colorectal Cancer Subtypes Classified by Fusobacterium Nucleatum in Tumor Tissue. JAMA Oncol. 2017; 10.

146. Tjalsma H, Boleij A, Marchesi JR, Dutilh BE. A bacterial driver-passenger model for colorectal cancer: beyond the usual suspects. Nat Rev. Microbiol. 2012; 10(8): 575-582.

147. Poutahidis T, Erdman SE. Commensal bacteria modulate the tumor microenvironment. Cancer Lett. 2016; 380(1): 356-358.

148. Erdman SE, Poutahidis T. Gut microbiota modulate host immune cells in cancer development and growth. Free Radic. Biol. Med. 2017; 105:28-34.

149. Langley RR, Fidler IJ. The seed and soil hypothesis revisited--the role of tumor-stroma interactions in metastasis to different organs. Int. J Cancer. 2011; 128(11): 2527-2535.

150. Andersson-Rolf A, Zilbauer M, Koo BK, Clevers H. Stem Cells in Repair of Gastrointestinal Epithelia. Physiology. (Bethesda. ). 2017; 32(4): 278-289.

151. Dean M. ABC transporters, drug resistance, and cancer stem cells. J. Mammary. Gland. Biol. Neoplasia. 2009; 14(1): 3-9.

152. DeMarini DM. Genotoxicity of tobacco smoke and tobacco smoke condensate: a review. Mutat. Res. 2004; 567(23): 447-474.

153. Vanharanta S, Massague J. Origins of metastatic traits. Cancer Cell. 2013; 24(4): 410-421.

154. Massague J, Batlle E, Gomis RR. Understanding the molecular mechanisms driving metastasis. Mol. Oncol. 2017; 11(1): 3-4.

155. Greco FA. Cancer of unknown primary site: still an entity, a biological mystery and a metastatic model. Nat. Rev. Cancer. 2014; 14(1): 3-4.

156. Pavlidis N, Pentheroudakis G. Cancer of unknown primary site. Lancet. 2012; 379(9824): 1428-1435.

157. Varadhachary GR, Raber MN. Cancer of unknown primary site. N. Engl. J. Med. 2014; 371(8): 757-765.

158. Varadhachary GR. Carcinoma of Unknown Primary Site. The Poster Child for Personalized Medicine? JAMA Oncol 2015; 1(1): 19-21.

159. Thiery JP, Acloque H, Huang RY, Nieto MA. Epithelial-mesenchymal transitions in development and disease. Cell. 2009; 139(5): 871-890.

160. Lim J, Thiery JP. Epithelial-mesenchymal transitions: insights from development. Development. 2012; 139(19): 3471-3486.

161. Nieto MA. Epithelial plasticity: a common theme in embryonic and cancer cells. Science. 2013; 342(6159): 1234850 .

162. Suarez-Carmona M, Lesage J, Cataldo D, Gilles C. EMT and inflammation: inseparable actors of cancer progression. Mol. Oncol. 2017; 10-0261.

163. Karlsson MC, Gonzalez SF, Welin J, Fuxe J. Epithelial-mesenchymal transition in cancer metastasis through the lymphatic system. Mol. Oncol. 2017; 10-0261.

164. Yeung KT, Yang J. Epithelial-mesenchymal transition in tumor metastasis. Mol. Oncol. 2017; 11(1): 28-39.

165. Liao TT, Yang MH. Revisiting epithelial-mesenchymal transition in cancer metastasis: the connection between epithelial plasticity and stemness. Mol. Oncol. 2017; 10-0261.

166. Imitola J, Raddassi K, Park KI, Mueller FJ, Nieto M, Teng YD, Frenkel D, Li J, Sidman RL, Walsh CA, Snyder EY, Khoury SJ. Directed migration of neural stem cells to sites of CNS injury by the stromal cell-derived factor 1alpha/CXC chemokine receptor 4 pathway. Proc. Natl. Acad. Sci. U. S. A. 2004; 101(52): 18117-18122.

167. Fitzmaurice C, Dicker D, Pain A, Hamavid H, Moradi-Lakeh M, MacIntyre MF, Allen C, Hansen G, Woodbrook R, Wolfe C, Hamadeh RR, Moore A, Werdecker A et al. The Global Burden of Cancer 2013. JAMA Oncol. 2015; 1(4): 505-527. 
168. Praud D, Rota M, Rehm J, Shield K, Zatonski W, Hashibe M, La Vecchia C, Boffetta P. Cancer incidence and mortality attributable to alcohol consumption. Int. J. Cancer. 2016; 138(6): 1380-1387.

169. Bagnardi V, Rota M, Botteri E, Tramacere I, Islami F, Fedirko V, Scotti L, Jenab M, Turati F, Pasquali E, Pelucchi $\mathrm{C}$, Galeone $\mathrm{C}$, Bellocco R et al. Alcohol consumption and site-specific cancer risk: a comprehensive dose-response meta-analysis. Br. J. Cancer. 2015; 112(3): 580-593.

170. International Agency for Research on Cancer. Alcohol drinking. IARC monographs on the evaluation of carcinogenic risks to humans, vol 44. Lyon: IARC, 1988. Updated in Volume 100E (2012): http://monographs.iarc.fr/ENG/Monographs/vol100E/mono100E-11.pdf.

171. Burki TK. Low public awareness of link between cancer and alcohol. Lancet Oncol. 2016; 17(5): e184-2045.

172. Baan R, Grosse Y, Lauby-Secretan B, El Ghissassi F, Bouvard V, Benbrahim-Tallaa L, Guha N, Islami F, Galichet L, Straif K. Carcinogenicity of radiofrequency electromagnetic fields. Lancet Oncol. 2011; 12(7): 624-626.

173. Non-ionizing radiation, Part 2: Radiofrequency electromagnetic fields IARC Monogr Eval. Carcinog. Risks Hum. 2013; 102(Pt 2): 1-460.

174. Pedersen C, Johansen C, Schuz J, Olsen JH, Raaschou-Nielsen O. Residential exposure to extremely low-frequency magnetic fields and risk of childhood leukaemia, CNS tumour and lymphoma in Denmark. Br. J. Cancer. 2015; 113(9): 1370-1374.

175. Crespi CM, Vergara XP, Hooper C, Oksuzyan S, Wu S, Cockburn M, Kheifets L. Childhood leukaemia and distance from power lines in California: a population-based case-control study. Br. J. Cancer. 2016; 115(1): 122128.

176. Schuz J. Exposure to extremely low-frequency magnetic fields and the risk of childhood cancer: update of the epidemiological evidence. Prog. Biophys. Mol. Biol. 2011; 107(3): 339-342.

177. Electromagnetic fields (EMF). Available online: http://www.who.int/peh-emf/en/

178. Kheifets L, Repacholi M, Saunders R, van Deventer E. The sensitivity of children to electromagnetic fields. Pediatrics. 2005; 116(2): e303-e313.

179. Bonnet D, Dick JE. Human acute myeloid leukemia is organized as a hierarchy that originates from a primitive hematopoietic cell. Nat. Med. 1997; 3(7): 730-737.

180. Hope KJ, Jin L, Dick JE. Acute myeloid leukemia originates from a hierarchy of leukemic stem cell classes that differ in self-renewal capacity. Nat. Immunol. 2004; 5(7): 738-743.

181. Reya T, Morrison SJ, Clarke MF, Weissman IL. Stem cells, cancer, and cancer stem cells. Nature. 2001; 414(6859): 105-111.

182. Huntly BJ, Gilliland DG. Leukaemia stem cells and the evolution of cancer-stem-cell research. Nat. Rev. Cancer. 2005; 5(4): 311-321.

183. Corces-Zimmerman MR, Majeti R. Pre-leukemic evolution of hematopoietic stem cells: the importance of early mutations in leukemogenesis. Leukemia. 2014; 28(12): 2276-2282.

184. Mikkola HK, Orkin SH. The journey of developing hematopoietic stem cells. Development. 2006; 133(19): 3733 3744.

185. Fernandez KS, de Alarcon PA. Development of the hematopoietic system and disorders of hematopoiesis that present during infancy and early childhood. Pediatr. Clin. North Am. 2013; 60(6): 1273-1289.

186. Ross CL, Siriwardane M, Almeida-Porada G, Porada CD, Brink P, Christ GJ, Harrison BS. The effect of lowfrequency electromagnetic field on human bone marrow stem/progenitor cell differentiation. Stem Cell Res. 2015; 15(1): 96-108.

187. Leone L, Podda MV, Grassi C. Impact of electromagnetic fields on stem cells: common mechanisms at the crossroad between adult neurogenesis and osteogenesis. Front Cell Neurosci. 2015; 9:228.

188. Maziarz A, Kocan B, Bester M, Budzik S, Cholewa M, Ochiya T, Banas A. How electromagnetic fields can influence adult stem cells: positive and negative impacts. Stem Cell Res. Ther. 2016; 7(1): 54-0312.

189. Saliev T, Mustapova Z, Kulsharova G, Bulanin D, Mikhalovsky S. Therapeutic potential of electromagnetic fields for tissue engineering and wound healing. Cell Prolif. 2014; 47(6): 485-493.

190. Fan W, Qian F, Ma Q, Zhang P, Chen T, Chen C, Zhang Y, Deng P, Zhou Z, Yu Z. 50 Hz electromagnetic field exposure promotes proliferation and cytokine production of bone marrow mesenchymal stem cells. Int. J. Clin. Exp. Med. 2015; 8(5): 7394-7404.

191. Adey WR. Tissue interactions with nonionizing electromagnetic fields. Physiol Rev. 1981; 61(2): 435-514.

192. Levin M. Bioelectromagnetics in morphogenesis. Bioelectromagnetics. 2003; 24(5): 295-315.

193. Zhao M, Song B, Pu J, Wada T, Reid B, Tai G, Wang F, Guo A, Walczysko P, Gu Y, Sasaki T, Suzuki A, Forrester $\mathrm{JV}$ et al. Electrical signals control wound healing through phosphatidylinositol-3-OH kinase-gamma and PTEN. Nature. 2006; 442(7101): 457-460.

194. Zhao M. Electrical fields in wound healing-An overriding signal that directs cell migration. Semin. Cell Dev. Biol. 2009; 20(6): 674-682.

195. McCaig CD, Song B, Rajnicek AM. Electrical dimensions in cell science. J. Cell Sci. 2009; 122(Pt 23): 4267-4276. 
196. Huo R, Ma Q, Wu JJ, Chin-Nuke K, Jing Y, Chen J, Miyar ME, Davis SC, Li J. Noninvasive electromagnetic fields on keratinocyte growth and migration. J. Surg. Res. 2010; 162(2): 299-307.

197. Iorio R, Bennato F, Mancini F, Colonna RC. ELF-MF transiently increases skeletal myoblast migration: possible role of calpain system. Int. J. Radiat. Biol. 2013; 89(7): 548-561.

198. Santini MT, Rainaldi G, Indovina PL. Cellular effects of extremely low frequency (ELF) electromagnetic fields. Int. J. Radiat. Biol. 2009; 85(4): 294-313.

199. Hawkins ED, Russell SM. Upsides and downsides to polarity and asymmetric cell division in leukemia. Oncogene. 2008; 27(55): 7003-7017.

200. Lopez-Lazaro M. A plausible biological mechanism by which extremely low-frequency electromagnetic fields increase the risk of childhood leukemia. Preprints 2016 doi:10. 20944/preprints201608.0187.v1; https://www.preprints.org/manuscript/201608.0187/v1

201. Siegel R, Ward E, Brawley O, Jemal A. Cancer statistics, 2011: the impact of eliminating socioeconomic and racial disparities on premature cancer deaths. CA Cancer J Clin. 2011; 61(4): 212-236.

202. Sporn MB, Suh N. Chemoprevention: an essential approach to controlling cancer. Nat. Rev. Cancer. 2002; 2(7): 537-543.

203. Goessling W, North TE, Loewer S, Lord AM, Lee S, Stoick-Cooper CL, Weidinger G, Puder M, Daley GQ, Moon RT, Zon LI. Genetic interaction of PGE2 and Wnt signaling regulates developmental specification of stem cells and regeneration. Cell. 2009; 136(6): 1136-1147.

204. Kurtova AV, Xiao J, Mo Q, Pazhanisamy S, Krasnow R, Lerner SP, Chen F, Roh TT, Lay E, Ho PL, Chan KS. Blocking PGE2-induced tumour repopulation abrogates bladder cancer chemoresistance. Nature. 2015; 517(7533): 209-213.

205. Cuzick J, Thorat MA, Bosetti C, Brown PH, Burn J, Cook NR, Ford LG, Jacobs EJ, Jankowski JA, La Vecchia C, Law M, Meyskens F, Rothwell PM et al. Estimates of benefits and harms of prophylactic use of aspirin in the general population. Ann. Oncol. 2015; 26(1): 47-57.

206. Chan AT, Ogino S, Fuchs CS. Aspirin use and survival after diagnosis of colorectal cancer. JAMA. 2009; 302(6): 649-658.

207. Jacobs EJ, Newton CC, Stevens VL, Campbell PT, Freedland SJ, Gapstur SM. Daily aspirin use and prostate cancer-specific mortality in a large cohort of men with nonmetastatic prostate cancer. J. Clin. Oncol. 2014; 32(33): 3716-3722.

208. Bibbins-Domingo K. Aspirin Use for the Primary Prevention of Cardiovascular Disease and Colorectal Cancer: U.S. Preventive Services Task Force Recommendation Statement. Ann. Intern. Med. 2016; 164(12): 836-845.

209. Couzin-Frankel J. Biomedicine. The bad luck of cancer. Science. 2015; 347(6217): 12.

210. Tomasetti C, Vogelstein B. Cancer risk: role of environment-response. Science. 2015; 347(6223): 729-731.

211. Gatenby RA. Is the Genetic Paradigm of Cancer Complete? Radiology. 2017; 284(1): 1-3.

212. Lopez-Lazaro M. Selective amino acid restriction therapy (SAART): a non-pharmacological strategy against all types of cancer cells. Oncoscience. 2015; 2(10): 857-866.

213. Lopez-Lazaro M. Two preclinical tests to evaluate anticancer activity and to help validate drug candidates for clinical trials. Oncoscience 2015; 2(2): 91-98.

214. Hahn WC, Counter CM, Lundberg AS, Beijersbergen RL, Brooks MW, Weinberg RA. Creation of human tumour cells with defined genetic elements. Nature. 1999; 400(6743): 464-468.

215. Hahn WC, Weinberg RA. Rules for making human tumor cells. N. Engl. J. Med. 2002; 347(20): 1593-1603.

216. Howard DJ, Briggs LA, Pritsos CA. Oxidative DNA damage in mouse heart, liver, and lung tissue due to acute sidestream tobacco smoke exposure. Arch. Biochem. Biophys. 1998; 352(2): 293-297.

217. Soto AM, Sonnenschein C. The somatic mutation theory of cancer: growing problems with the paradigm? Bioessays 2004; 26(10): 1097-1107.

218. Soto AM, Sonnenschein C. One hundred years of somatic mutation theory of carcinogenesis: is it time to switch? Bioessays. 2014; 36(1): 118-120.

219. Soto AM, Sonnenschein C. The tissue organization field theory of cancer: a testable replacement for the somatic mutation theory. Bioessays. 2011; 33(5): 332-340.

220. Bizzarri M, Cucina A. SMT and TOFT: Why and How They are Opposite and Incompatible Paradigms. Acta Biotheor. 2016; 64(3): 221-239.

221. Harguindey S, Orive G, Luis PJ, Paradiso A, Reshkin SJ. The role of $\mathrm{pH}$ dynamics and the $\mathrm{Na}(+) / \mathrm{H}(+)$ antiporter in the etiopathogenesis and treatment of cancer. Two faces of the same coin-one single nature. Biochim. Biophys. Acta 2005; 1756(1): 1-24.

222. Harguindey S, Reshkin SJ. The new $\mathrm{pH}$-centric anticancer paradigm in Oncology and Medicine. Semin. Cancer Biol. 2017; 43:1-4.

223. Lopez-Lazaro M. A new view of carcinogenesis and an alternative approach to cancer therapy. Mol. Med. 2010; 16(3-4): 144-153. 
224. Kajstura J, Rota M, Hall SR, Hosoda T, D'Amario D, Sanada F, Zheng H, Ogorek B, Rondon-Clavo C, FerreiraMartins J, Matsuda A, Arranto C, Goichberg P et al. Evidence for human lung stem cells. N. Engl. J Med. 2011; 364(19): 1795-1806.

225. Bearzi C, Rota M, Hosoda T, Tillmanns J, Nascimbene A, De Angelis A, Yasuzawa-Amano S, Trofimova I, Siggins RW, Lecapitaine N, Cascapera S, Beltrami AP, D'Alessandro DA et al. Human cardiac stem cells. Proc. Natl. Acad. Sci. U. S. A. 2007; 104(35): 14068-14073.

226. Torre LA, Bray F, Siegel RL, Ferlay J, Lortet-Tieulent J, Jemal A. Global cancer statistics, 2012. CA Cancer J. Clin. 2015; 65(2): 87-108.

227. Torre LA, Siegel RL, Ward EM, Jemal A. Global Cancer Incidence and Mortality Rates and Trends--An Update. Cancer Epidemiol. Biomarkers Prev. 2016; 25(1): 16-27.

228. Siegel RL, Miller KD, Jemal A. Cancer statistics, 2016. CA Cancer J. Clin. 2016; 66(1): 7-30. 